ARTICLE

\title{
EAF2 mediates germinal centre B-cell apoptosis to suppress excessive immune responses and prevent autoimmunity
}

Yingqian Li1 ${ }^{1,2,3}$, Yoshimasa Takahashi ${ }^{4}$, Shin-ichiro Fujii ${ }^{5}$, Yang Zhou' ${ }^{1}$ Rongjian Hong ${ }^{1}$, Akari Suzuki ${ }^{6}$, Takeshi Tsubata7, Koji Hase ${ }^{2,3}$ \& Ji-Yang Wang ${ }^{1,7}$

Regulated apoptosis of germinal centre (GC) B cells is critical for normal humoral immune responses. ELL-associated factor 2 (EAF2) regulates transcription elongation and has been shown to be an androgen-responsive potential tumour suppressor in prostate by inducing apoptosis. Here we show that EAF2 is selectively upregulated in GC B cells among various immune cell types and promotes apoptosis of GC B cells both in vitro and in vivo. EAF2 deficiency results in enlarged GCs and elevated antibody production during a T-dependent immune response. After immunization with type II collagen, mice lacking EAF2 produce high levels of collagen-specific autoantibodies and rapidly develop severe arthritis. Moreover, the mutant mice spontaneously produce anti-dsDNA, rheumatoid factor and anti-nuclear antibodies as they age. These results demonstrate that EAF2-mediated apoptosis in GC B cells limits excessive humoral immune responses and is important for maintaining self-tolerance.

\footnotetext{
${ }^{1}$ Department of Immunology, School of Basic Medical Sciences, Fudan University, Shanghai 200032, China. ${ }^{2}$ Division of Mucosal Barriology, International Research and Development Center for Mucosal Vaccines, The Institute of Medical Science, The University of Tokyo, Tokyo 142-0054, Japan. ${ }^{3}$ Department of Biochemistry, Faculty of Pharmacy, Keio University, Tokyo 105-8512, Japan. ${ }^{4}$ Department of Immunology, National Institute of Infectious Diseases, Tokyo 162-8640, Japan. ${ }^{5}$ Laboratory for Immunotherapy, Center for Integrative Medical Sciences, RIKEN, Yokohama 230-0045, Japan. ${ }^{6}$ Laboratory for Autoimmune Diseases, Center for Integrative Medical Sciences, RIKEN, Yokohama 230-0045, Japan. 7 Department of Immunology, Medical Research Institute, Tokyo Medical and Dental University, Tokyo 113-8510, Japan. Correspondence and requests for materials should be addressed to K.H. (email: hase-kj@pha.keio.ac.jp) or to J.-Y.W. (email: wang@fudan.edu.cn).
} 
G erminal centre (GC) B cells represent a unique cell population that is induced during an adaptive immune response. These rapidly dividing cells undergo Ig gene somatic hypermutation (SHM) and class switch recombination, and those with high affinity for the foreign antigen $(\mathrm{Ag})$ are selected to differentiate into plasma cells or memory B cells. Studies thus far indicate that regulated apoptosis of GC B cells is important for appropriate GC formation and optimal humoral immune responses ${ }^{1}$. In addition, apoptosis is thought to be involved in the elimination of self-reactive GC B cells ${ }^{2-5}$, which can be generated by SHM (refs 5-8). Two principal signalling pathways initiate apoptosis in GC B cells, ${ }^{9}$. The intrinsic pathway is regulated by Bcl-2 family members such as $B c l-2$ (refs 11,12), Bcl-xL (ref. 13) and $M c l-1$ (ref. 14). On the other hand, the extrinsic pathway is activated when death receptors such as FAS (CD95) on the B-cell surface are engaged by cognate ligands of the tumour necrosis factor family ${ }^{15-17}$.

To identify GC B-cell-specific apoptosis inducer that contributes to the normal humoral immune response and the elimination of self-reactive GC B cells, we searched for apoptosis-related genes highly expressed in GC B cells. We compared gene expression profiles of a variety of different immune cell subpopulation and found the ELL (eleven-nineteen lysine-rich leukaemia)-associated factor 2 (Eaf2) to be highly expressed in GC B cells but not in many other immune cell types including various $\mathrm{T}$ cell and dendritic cell subsets. The EAF family members EAF1 and EAF2 were originally identified as novel proteins interacting with ELL, a fusion partner of the multi-lineage leukaemia gene in the $t(11 ; 19)(\mathrm{q} 23 ; \mathrm{p} 13.1)$ recurrent chromosomal translocation associated with acute myeloid leukaemia ${ }^{18,19}$. U19, an androgen-responsive gene in the prostate ${ }^{20}$, was independently shown to encode EAF2 (ref. 21). By binding to ELL, EAF1 and EAF2/U19 efficiently stimulate ELL elongation activity ${ }^{22}$. In vitro and in vivo functional assays have revealed that EAF2/U19 induces growth arrest and apoptosis of prostate cancer cells ${ }^{21,23}$. Eaf2/U19-knockout mice on a C57BL/6J background developed prostatic intraepithelial neoplasia ${ }^{24}$. Collectively, these observations suggested a critical role for EAF2 in the induction of apoptosis and suppression of tumourigenesis.

In the present study, we provide in vitro and in vivo evidence that EAF2 mediates apoptosis of GC B cells but not naive B and other immune cell types. EAF2 deficiency causes not only enlarged GC and elevated humoral immune responses but also high susceptibility to collagen-induced arthritis (CIA) and autoantibody production. These findings identify EAF2 as a GC B-specific apoptosis inducer in the immune system that functions to maintain the balance between immunity and tolerance.

\section{Results}

Eaf2 is an apoptosis inducer highly expressed by GC B cells. A comparison of gene expression profiles among various immune cell subpopulation identified Eaf2, a gene implicated in the apoptosis of prostate cancer cells ${ }^{21}$, as selectively upregulated in the GC B cells but not in naive B or B cells activated in vitro by the various stimuli (Supplementary Fig. 1a), or in spleen T cells
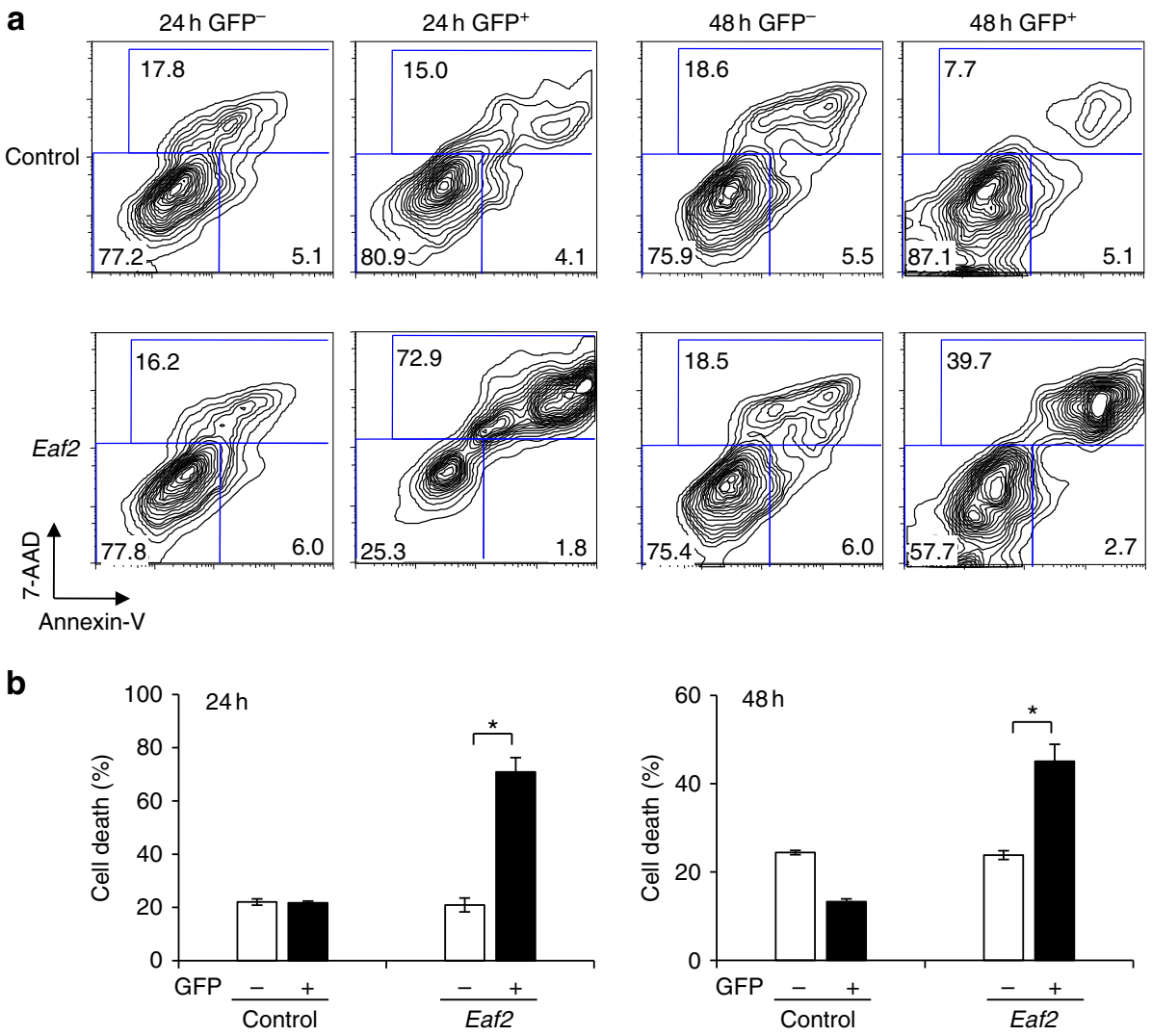

Figure 1 | Overexpression of Eaf2 induces the death of normal B cells. Purified spleen B cells $\left(1 \times 10^{5}\right.$ per $\left.\mathrm{ml}\right)$ were stimulated with $10 \mu \mathrm{g} \mathrm{ml}{ }^{-1}$ of LPS for $24 \mathrm{~h}$ and then transduced with retrovirus expressing GFP (control) or EAF2-IRES-GFP (Eaf2). The cells were further cultured for 24 and $48 \mathrm{~h}$ and analysed for cell death by Annexin-V and 7-AAD staining. (a) Representative FACS profiles of B cells cultured for 24 and $48 \mathrm{~h}$. (b) Percentages of apoptotic $\left(\right.$ Annexin- $\left.V^{+} 7-A A D^{-}\right)+$dead $\left(7-A A D^{+}\right)$cells in gated GFP ${ }^{-}$and GFP ${ }^{+}$population. Summary of the results of three independent experiments. ${ }^{\star} P<0.05$ (paired $t$-test). 
before and after $\mathrm{T}$ cell receptor stimulation, sorted conventional and plasmacytoid dendritic cells, as well as many other immune cell types (Supplementary Fig. 1b). This expression pattern suggested that EAF2 might be involved in the apoptosis of GC B cells. We therefore first examined whether EAF2 plays a role in B-cell apoptosis. Purified spleen B cells activated with lipopolysaccharide (LPS) were transduced with control green fluorescent protein (GFP) or EAF2-IRES-GFP retrovirus and analysed for cell death in gated $\mathrm{GFP}^{-}$and $\mathrm{GFP}^{+}$cells. As shown in Fig. 1a upper panels, transduction of the control GFP virus did not increase the cell death at either $24 \mathrm{~h}$ (left 2 panels) or $48 \mathrm{~h}$ (right 2 panels) after virus transduction (compare the virus- transduced $\mathrm{GFP}^{+}$with the non-transduced $\mathrm{GFP}^{-}$population). In contrast, transduction of the EAF2 retrovirus (Fig. 1a lower panels) greatly enhanced cell death at both 24 and $48 \mathrm{~h}$ as compared with either virus non-transduced $\mathrm{GFP}^{-}$cells or control virus-transduced cells. These results demonstrate that Eaf2 overexpression induces B-cell death (Fig. 1b).

EAF2 specifically mediates the apoptosis of GC B cells. To explore the function of EAF2 in vivo, we generated Eaf2 $2^{-1-}$ mice in pure C57BL/6 background (Supplementary Fig. 2a,b). Eaf2 ${ }^{-1-}$ mice developed normally without any apparent abnormalities and showed no signs of lymphoma and other
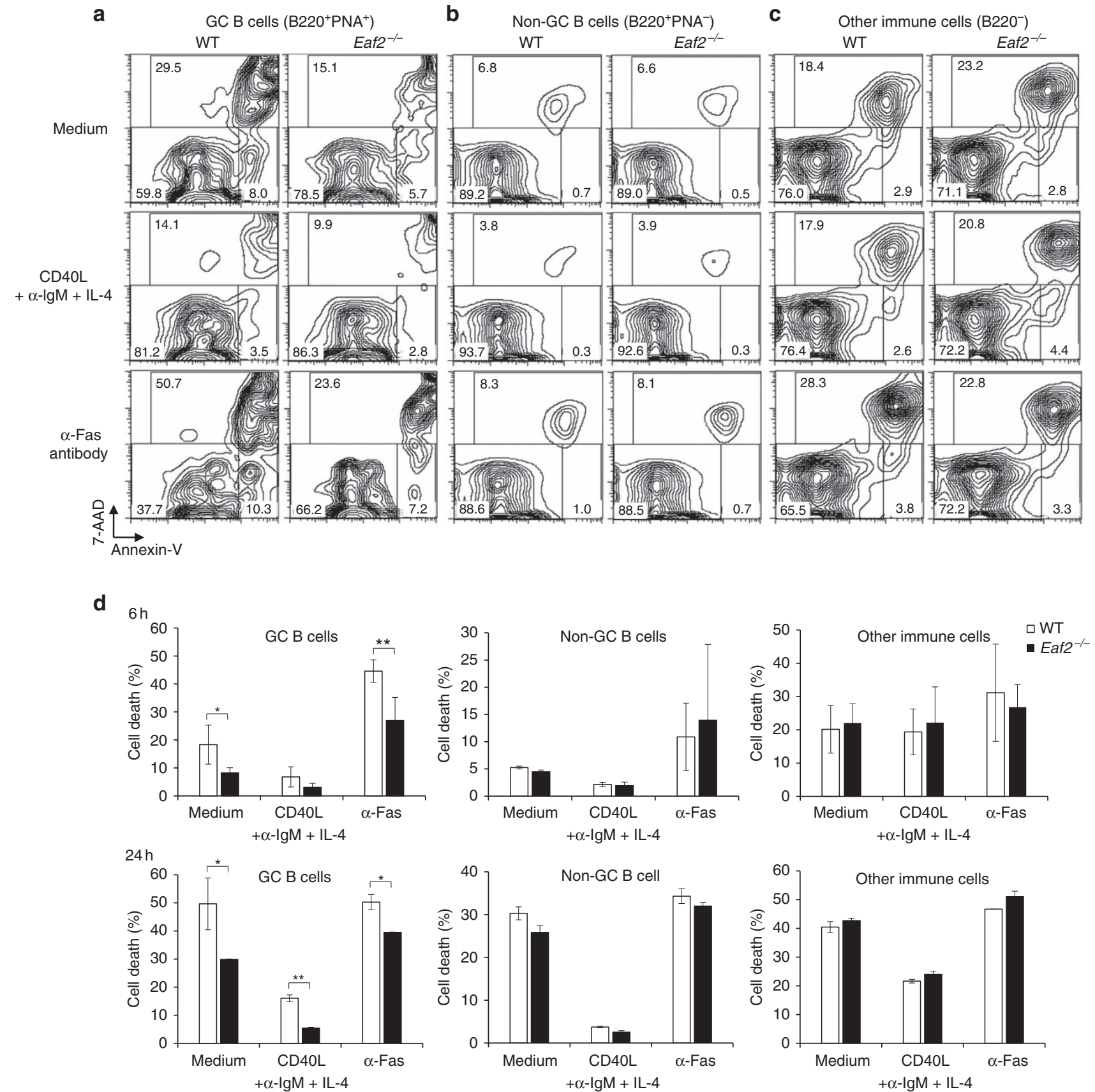

Figure 2 | GC B cells from Eaf2 ${ }^{-1}$ - mice show decreased cell death compared with WT GC B cells. Cells from Peyer's patches ( $10^{6}$ cells per ml) were cultured in medium alone or in the presence of CD4OL $+\alpha-\operatorname{lgM}+\mathrm{IL}-4$ or an agonistic anti-Fas Ab for $6 \mathrm{~h}$ and then analysed for cell death as in Fig. 1 in gated GC B cells (a), non-GC B (b) and other immune cells (c). (d) Summary of the results obtained with three pairs of WT and Eaf2 ${ }^{-/}-$mice. Upper panels, $6 \mathrm{~h}$ culture; Lower panels, $24 \mathrm{~h}$ culture. White bars, WT; Solid bars, Eaf2 ${ }^{-/-}{ }^{\star}{ }^{\star} P<0.05 ;{ }^{\star \star} P<0.01$ (paired $t$-test). 
tumours. Development and maturation of B and T cells appeared normal (Supplementary Fig. 3) and class switch recombination and B-cell proliferation in response to various stimuli were unaffected by EAF2 deficiency (Supplementary Fig. 4a,b). In addition, Eaf2 ${ }^{-1-}$ mice maintained under specific pathogen-free conditions had normal levels of serum Igs (Supplementary Fig. 4c). Therefore, EAF2 deficiency had no apparent effect on B-cell development and maturation possibly due to its low levels of expression in these cells (Supplementary Fig. 1a).

We next investigated whether GC B-cell death was affected in Eaf2 ${ }^{-1-}$ mice. Peyer's patches contain a relatively high proportion of GC B cells, as well as mature B and T cells, dendritic cells and macrophages. We therefore used them as a source of GC B and other immune cells, which were cultured under different conditions and analysed for cell death. As shown in Fig. 2a, B220 ${ }^{+}$PNA (peanut agglutinin) ${ }^{+} \mathrm{GC} \mathrm{B}$ cells from Eaf2 ${ }^{-}{ }^{-}$mice exhibited significantly reduced cell death compared with those from wild-type (WT) mice either in medium alone (upper panels) or in the presence of the $\alpha$-FAS $\mathrm{Ab}$ (lower panels), which triggers one of the extrinsic pathways of GC B-cell apoptosis ${ }^{9,10}$. In the presence of physiological B-cell stimulation conditions (CD40L $+\alpha-\operatorname{IgM}+\mathrm{IL}-4)$, Eaf2 - / - GC B cells also showed reduce cell death compared with WT GC B cells at $24 \mathrm{~h}$ of culture (Fig. 2d). These observations implicate that EAF2 deficiency not only enhanced spontaneous survival and suppressed FAS-mediated cell death, but also appeared to promote the survival of GC B cells receiving Ag stimulation and T-cell help. In contrast, death of the non-GC B $\left(\mathrm{B} 220^{+}\right.$ $\mathrm{PNA}^{-}$) cells (Fig. 2b) and other immune cells (B220 ${ }^{-}$; Fig. 2c) was not affected by EAF2 deficiency under these culture conditions, an observation consistent with the low levels of EAF2 expression in these cells (Supplementary Fig. 1).

Enlarged GC with fewer TUNEL ${ }^{+}$cells in Eaf2 ${ }^{-/-}$mice. To investigate whether EAF2 regulates GC B-cell apoptosis under physiological conditions, we next compared GC formation and GC B-cell apoptosis in WT and Eaf2 ${ }^{-7}-$ mice immunized with the T-dependent (T-D) Ag 4-hydroxy-3-nitrophenyl-acetyl (NP) coupled to chicken $\gamma$-globulin (CGG). Two weeks after the immunization, spleen sections were stained with PNA to identify GC B cells ${ }^{25}$. While the average numbers of GC per spleen section were similar between $\mathrm{WT}$ and $E a f 2^{-1-}$ mice, the GC in Eaf2 ${ }^{-1-}$ mice were significantly larger than those in WT mice (Fig. 3a, left panels). We measured the sizes of over twenty GC in each mouse and calculated the average size. The results of three pairs of WT and Eaf2 ${ }^{-1-}$ mice demonstrate that GC in Eaf2 ${ }^{-1}-$ mice were enlarged by twofold than in WT mice (Fig. 3a, right panel).

To explore whether the enlarged GC in Eaf2 ${ }^{-1-}$ mice were due to decreased cell death, we next analysed apoptosis in WT a

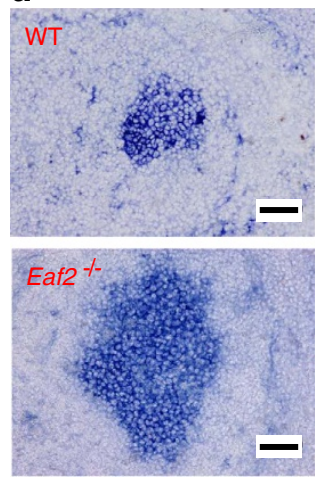

b

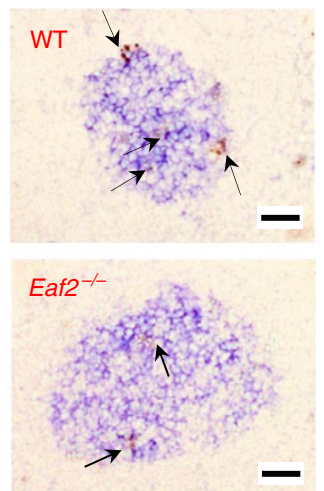

Ave. GC size per mouse
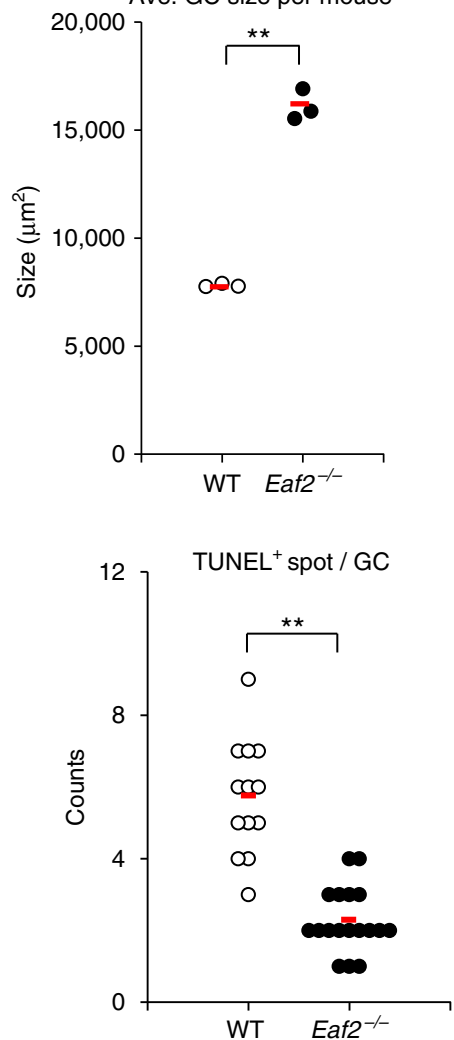

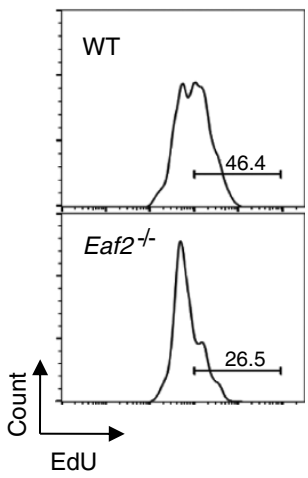

d

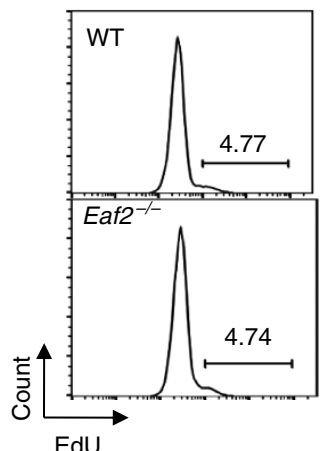

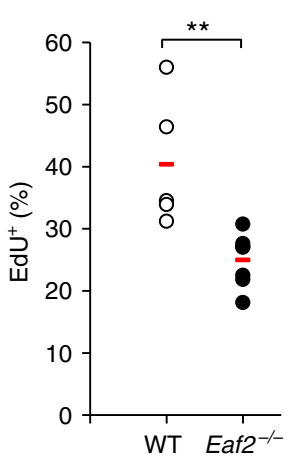

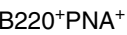

$\mathrm{B}^{2} 20^{+} \mathrm{PNA}^{-}$

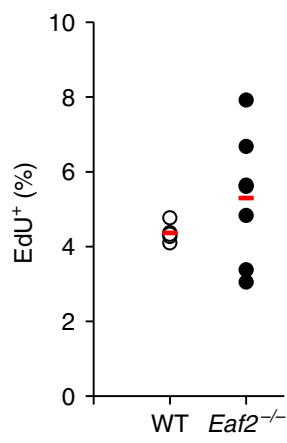

Figure 3 | Eaf2 ${ }^{-1}$ - mice have enlarged GC with decreased apoptosis compared with WT mice. GC formation in the spleen on day 14 after primary immunization with NP-CGG. (a) Left, representative PNA staining (blue) of spleen sections in WT and Eaf2-/- mice. Right, average size of GC in each mouse. Over $20 \mathrm{GC}$ were measured in each mouse and the average size was calculated. Each symbol represents the average GC size in one mouse. The results of three pairs of WT and Eaf2- ${ }^{-1}$ mice are shown. (b) Left, representative TUNEL staining (brown spots indicated by arrows are TUNEL ${ }^{+}$), Right, $\mathrm{TUNEL}^{+}$spot numbers per each GC. Brown TUNEL ${ }^{+}$spots in 7-10 GC of each mouse were counted. The results of two pairs of WTand Eaf2 ${ }^{-/-}$mice are

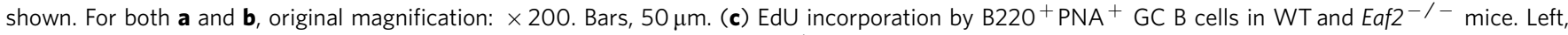
representative FACS profiles of EdU levels; right, results of 5 WT and 6 Eaf2 ${ }^{-/-}$mice. (d) EdU incorporation by B220 ${ }^{+}$PNA ${ }^{-}$non-GC B cells in WT and Eaf2 ${ }^{-/}$mice. The red bar indicates the mean value of each group. ${ }^{\star \star} P<0.01$ (unpaired $t$-test). 
and Eaf2 $2^{-1}$ GC B cells by combining a TUNEL assay and PNA staining (Fig. 3b, left panels). Within GC, the majority of TUNEL $^{+}$cells/nuclei were contained within tingible body macrophages as clumps of two to five cells ${ }^{26}$. We analysed 7-10 GC per mouse and the results of two pairs of mice revealed a significant reduction of the TUNEL ${ }^{+}$apoptotic cells in Eaf2 ${ }^{-1-}$ mice (Fig. 3b, right panel). These results provide physiological evidence that EAF2 is involved in the apoptosis of GC B cells and that lack of EAF2 results in enlarged GC.

The increased survival of GC B cells in Eaf2 ${ }^{-1-}$ mice may result in an accumulation of non-proliferating $B$ cells. To explore this possibility, we immunized mice with NP-CGG and analysed EdU (5-ethynyl-2'-deoxyuridine) incorporation 2 weeks later. As shown in Fig. 3c, GC B cells $\left(\mathrm{B}_{220}{ }^{+} \mathrm{PNA}^{+}\right)$in Eaf2 ${ }^{-1-}$ mice indeed contained a significantly decreased percentage of $\mathrm{EdU}^{+}$ cells than did GC B cells in WT mice. As a control, non-GC B cells $\left(\mathrm{B}_{22} 20^{+} \mathrm{PNA}^{-}\right)$in WT and Eaf2 ${ }^{-1-}$ mice contained a similarly low percentage of EdU ${ }^{+}$cells (Fig. 3d). These results suggest that Eaf2 $2^{-1-}$ mice contain an increased proportion of non-proliferating GC B cells.

Increased numbers of the Ag-specific GC and memory B cells. We immunized mice with NP-CGG and 2 weeks later stained splenocytes with B220, NIP-BSA, $\mathrm{IgG}_{1}$ and $\mathrm{CD} 38$ to determine the numbers of NIP-binding (that is, NP-specific) GC B $\left(\mathrm{IgG}_{1}^{\text {dull }} \mathrm{CD} 38^{\text {dull }}\right.$ ) and memory B ( $\left(\mathrm{gG}_{1}^{\text {high }} \mathrm{CD} 38^{+}\right.$) cells (Fig. $\left.4 \mathrm{a}-\mathrm{c}\right)$. At 2 weeks after immunization, both the percentages (Fig. 4c) and the numbers (Fig. 4d) of NP-specific GC B and memory B cells were increased in Eaf2 ${ }^{-1-}$ mice as compared with WT mice, consistent with the enlarged GC in Eaf2 ${ }^{-1-}$ mice. However, the numbers of the NP-specific GC B and memory B cells in Eaf2 $2^{-1-}$ mice were reduced to levels similar to those in WT mice at 6 and 9 weeks after immunization (Supplementary Fig. 5a). These observations suggest that the Ag-specific GC B and memory B cells were increased transiently during the peak of the GC reaction but returned to normal levels thereafter.

Elevated primary immune response in Eaf2 ${ }^{-1-}$ mice. The enlarged GC in association with increased Ag-specific GC B and memory B cells in Eaf2 $2^{-1}$ - mice raises the possibility that EAF2 deficiency may cause excessive humoral immune response. Indeed, Eaf2 ${ }^{-1}$ mice produced elevated levels of NP-specific total $\mathrm{IgG}_{1} \mathrm{Ab}$ (measured with NP25) from 2 to 8 wks after immunization with NP-CGG (Fig. 5a, upper panel). The production of the high-affinity NP-Ab (measured with NP2) was also increased in Eaf2 $2^{-1-}$ mice, but from a later time point after immunization (Fig. 5a, lower panel). The elevated production of both total and high-affinity NP-specific Ab was associated with significantly increased numbers of the total and high-affinity $\mathrm{Ab}$-forming cells (AFCs) both in the spleen and bone marrow (BM) (Fig. 5b). When the mice were boosted with NP-CGG in PBS, Eaf2 $2^{-1}$ mice had an increased Ab response compared with WT mice, but the magnitude of the increase was similar to that observed during the primary response (Fig. 5a). To clarify whether the memory response was affected by EAF2 deficiency, we immunized WT and Eaf2 ${ }^{-1-}$ mice with NP-CGG in alum and 9 weeks later transferred their spleen B cells together with CGG-primed $\mathrm{T}$ cells into Rag1 ${ }^{-/-}$mice. Administration of a

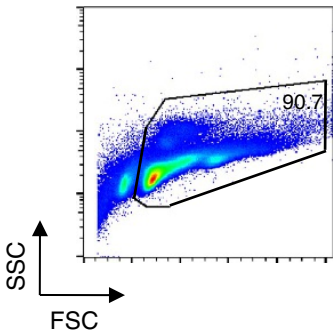

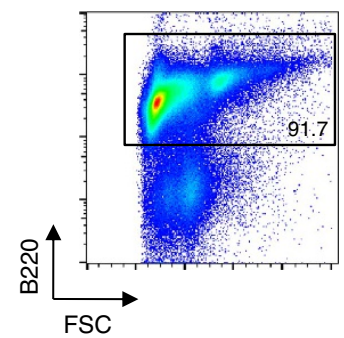

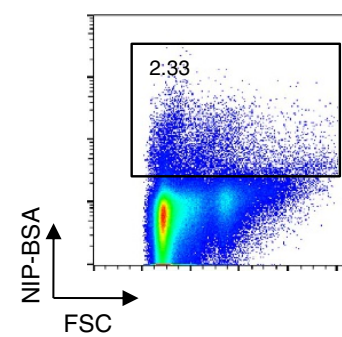

d b

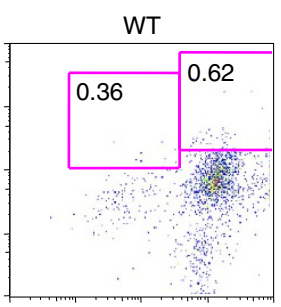

c

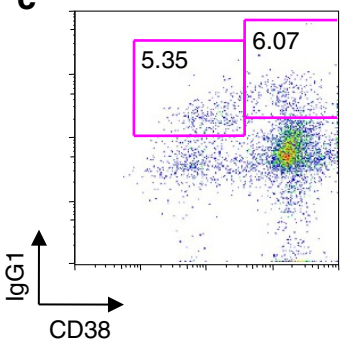

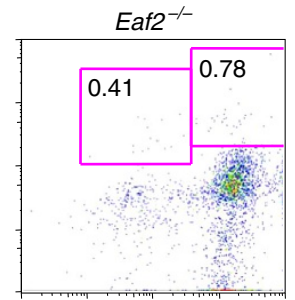

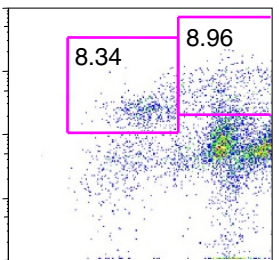

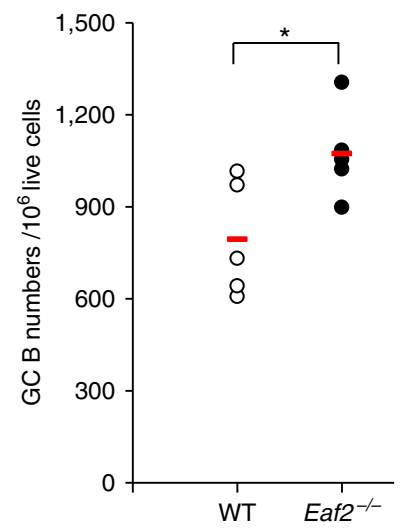

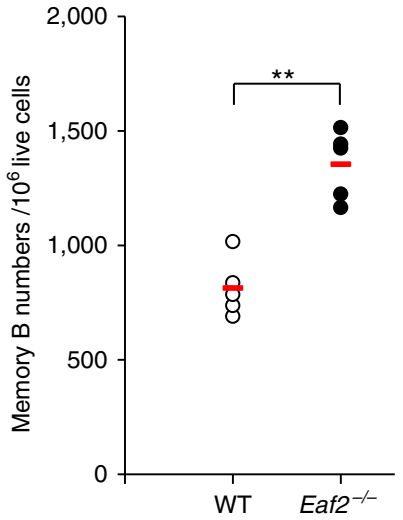

Figure 4 | Increased frequency of Ag-specific GC and memory B cells after immunization. Spleen B cells were purified 2 weeks after immunization with NP-CGG and stained with FITC-labelled IgG, PE-conjugated NIP 26 -BSA, APC-conjugated anti-CD38 and PE-Cy7-labelled anti-B220. GC B (NIP binding/ $\mathrm{B}_{22} 0^{+} / / \mathrm{IgG}_{1}{ }^{\text {dull }} / \mathrm{CD} 38^{\text {dull }}$ ) and memory B cells (NIP binding/B220 ${ }^{+} / \mathrm{IgG}_{1}^{\text {high }} / \mathrm{CD} 38^{+}$) were enumerated. (a) Gating strategy for the analysis of GC B and memory B cells. The live B220 ${ }^{+}$NIP-binding cells were analysed for CD38 and IgG $\mathrm{G}_{1}$ expression. (b) Before immunization. (c) Two weeks after immunization. Left panel, WT mice; right panel, Eaf2 ${ }^{-/-}$mice. (d) The tabulated results of five pairs of WT and Eaf2 $2^{-/-}$mice. Left, GC B cells; right, memory B cells. Open circles, WT mice; Solid circles, Eaf2 ${ }^{-/}$- mice. The red bar indicates the mean of five mice. ${ }^{\star} P<0.05$; ${ }^{\star \star} P<0.01$ (unpaired $t$-test). 
a

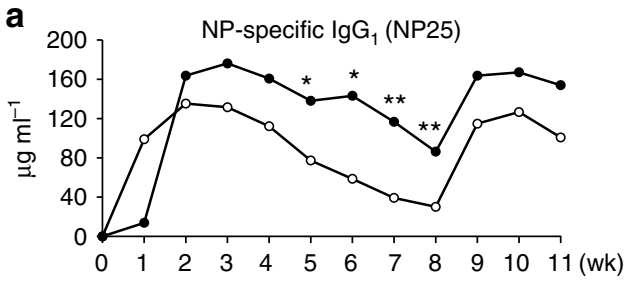

$N P$-specific $\lg G_{1}(N P 2)$

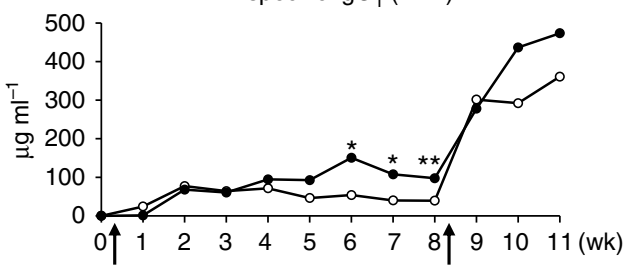

\section{b}
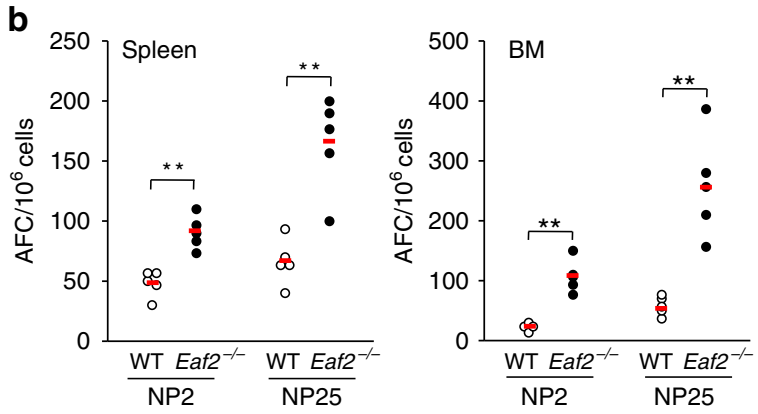

e

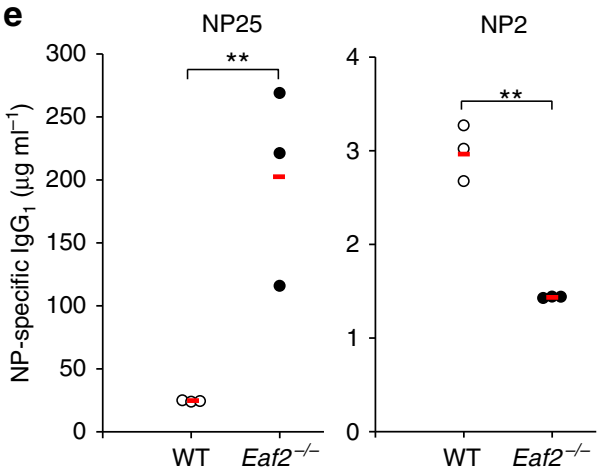

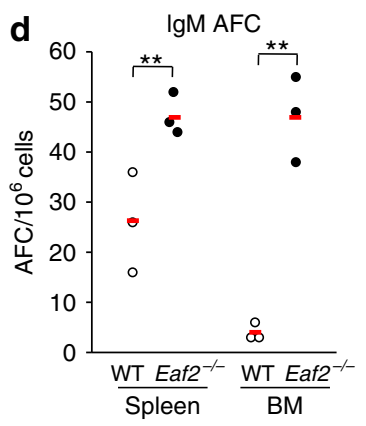
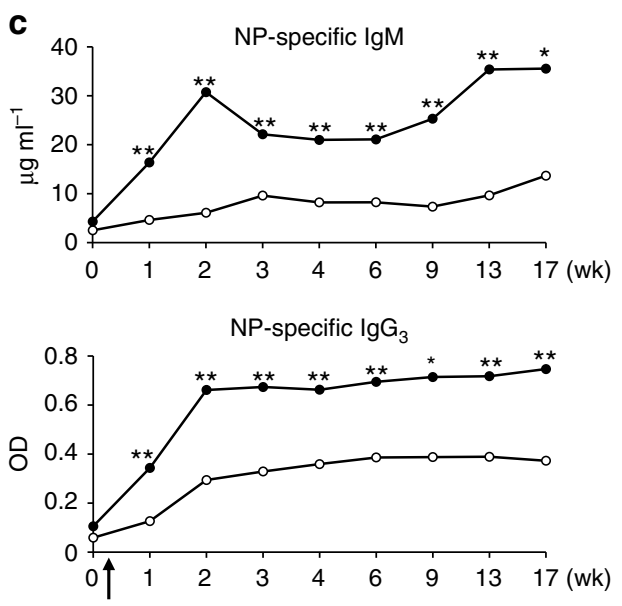

f

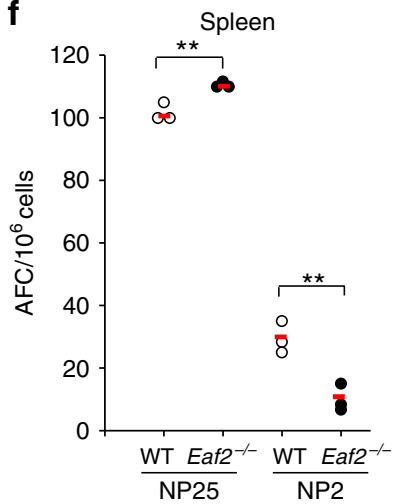

Figure 5 | Increased NP-specific Ab in immunized Eaf2 ${ }^{-/-}$mice. (a) Five pairs of WT and Eaf2 ${ }^{-/-}$mice were immunized with $10 \mu \mathrm{g}$ of NP-CGG in alum. Serum levels of NP-specific $\operatorname{lgG}_{1}$ Ab were measured with NP25-BSA (upper) and NP2-BSA (lower) at the indicated time points as described in Methods section. (b) AFC in spleen (left) and BM (right) at 6 weeks after NP-CGG immunization. NP2 and NP25 detect high affinity and total NP-specific AFC, respectively. (c) NP-specific lgM (upper) and lgG (lower) serum Ab levels after immunization with NP-Ficoll. The results of five pairs of WT and Eaf2 $2^{-/-}$mice are shown. (d) NP-specific IgM AFC in the spleen and BM at 21 weeks after NP-Ficoll immunization. Three pairs of WT and Eaf2 ${ }^{-/-}$mice were analysed. (e) and (f), Rag1 ${ }^{-/-}$mice reconstituted with WT T + WT B or WT T + Eaf2 ${ }^{-/-}$B cells were immunized with NP-CGG and analysed for (e) NP-specific total $\lg G_{1} A b$ (NP25) and high-affinity $\lg G_{1} A b(N P 2)$ in the serum and (f) AFC in the spleen. Open circles, Rag1-/ - mice reconstituted with WT T + WT B cells; Solid circles, Rag ${ }^{-/-}$mice reconstituted with WT T + Eaf $2^{-/}-$B cells. Arrows in a and $\mathbf{c}$ indicate immunization times. The red bar indicates the mean value of each group. ${ }^{\star} P<0.05$; ${ }^{\star \star} P<0.01$ (unpaired $t$-test).

NP-CGG in PBS into the recipient mice revealed similar secondary responses by WT and Eaf2 ${ }^{-1-}$ memory B cells, as shown by the production of similar amounts of both total and highaffinity NP-specific Ab (Supplementary Fig. 5b) and the generation of similar numbers of the total and high-affinity AFC (Supplementary Fig. 5c). Collectively, the enlarged GC and the increased numbers of the Ag-specific GC B and memory B cells during the peak of GC reaction resulted in increased numbers of $\mathrm{AFC}$ and elevated $\mathrm{Ab}$ production during the primary response. However, the numbers of both GC B and memory B cells in Eaf2 ${ }^{-1-}$ mice were reduced to normal levels at later time points during the primary immune response and the memory response was not enhanced by EAF2 deficiency.

We also challenged the mice with the T-independent (T-I) Ag NP-Ficoll. The production of NP-specific IgM and $\operatorname{IgG}_{3} \mathrm{Ab}$ was significantly increased in Eaf2 ${ }^{-1-}$ mice as compared with WT mice (Fig. 5c). This increase was sustained for at least 3-4 months after immunization, which was accompanied by increased numbers of NP-specific AFC (Fig. 5d). Although in general T-I $\mathrm{Ag}$ do not trigger a strong $\mathrm{GC}$ reaction in $\mathrm{C} 57 \mathrm{BL} / 6$ mice, it has been reported that NP-Ficoll was able to induce $\mathrm{PNA}^{+}$follicular clusters that resembled GC formed during T-D responses ${ }^{27}$. 
EAF2 might also mediate apoptosis of such $\mathrm{PNA}^{+}$follicular $\mathrm{B}$ cells and/or the proliferating cells outside the follicle that respond to the NP-Ficoll, and its absence could have resulted in increased survival of these cells, leading to elevated T-I Ab responses. Therefore, EAF2 suppresses Ab production to both T-D and T-I Ag for prolonged periods after immunization.

To clarify whether the enhanced $\mathrm{Ab}$ production was due to a B-cell-intrinsic defect, purified WT or Eaf2 ${ }^{-1}$ - spleen B cells were mixed with purified WT spleen $\mathrm{T}$ cells and transferred into Rag1 $1^{-1-}$ mice. The recipient mice were then immunized with NP-CGG and analysed for humoral immune responses. Rag1 - /mice that received $E a f 2^{-1-}$ B cells had significantly elevated production of NP-specific total $\mathrm{IgG}_{1} \mathrm{Ab}$ (Fig. 5e, left panel) and AFC (Fig. 5f) than those that received WT B cells. Although production of NP-specific high-affinity $\mathrm{Ab}$ and $\mathrm{AFC}$ was low in the reconstituted mice, Rag1 ${ }^{-1-}$ mice received Eaf2 ${ }^{-1}-\mathrm{B}$ cells had decreased production of high-affinity $\mathrm{Ab}$ (Fig. 5e, right panel) and AFC (Fig. 5f) than those received WT B cells. The frequency of GC $\mathrm{B}$ cells appeared to be slightly increased in $\mathrm{Rag}^{-/}-$mice received Eaf2 ${ }^{-1}-$ B than those received WT B cells (Supplementary Fig. 6a, left panel). The frequency of memory B (Supplementary Fig. 6a, right panel) and T-follicular helper cells (Supplementary Fig. 6b) was similar between Rag1 ${ }^{-1-}$ mice received either WT or Eaf $2^{-1-}$ B cells. These results demonstrate that the enhanced production of NP-specific total $\mathrm{Ab}$ and $\mathrm{AFC}$ is due to a B-cellintrinsic defect.

Ab affinity maturation in Eaf $^{-/-}$mice. The finding of decreased apoptosis of GC B cells and the enlarged GC during the primary immune response in Eaf2 $2^{-/}$mice suggested that $\mathrm{Ab}$ affinity maturation might be compromised due to survival of lowaffinity B cells. Analysis of SHM in the $\mathrm{J}_{\mathrm{H}} 4$ intronic region, which represents unselected mutations ${ }^{28-30}$, revealed a similar mutation frequency in WT and Eaf2 $2^{-1-}$ mice (Fig. 6a, left two columns). Therefore, EAF2 deficiency did not seem to affect the AIDtriggered mutation induction process. We next sequenced the $V_{H} 186.2$ gene, the primary $\mathrm{V}$ gene used in the response to NP in C57BL/6 mice. The frequency and patterns of mutations in the $V_{H} 186.2$ gene is affected by the selection process for high-affinity $\mathrm{Ab}$ in the GC. As shown in Fig. 6a right two columns, the total mutation frequency was slightly decreased in Eaf2-1- GC B cells ( 0.71 versus $0.89 \%$ in WT GC B cells). Ab affinity against NP increases $\sim 10$-fold by a single aa substitution (tryptophan to leucine at position 33, W33L) in the complementarity determining region 1. As shown in Fig. $6 \mathrm{~b}$ left panel, the frequency of W33L was similar between WT (68\%) and Eaf2 ${ }^{-/-}$(66\%) GC B cells, suggesting that GC B cells harbouring this aa substitution were normally positively selected in Eaf2 $2^{-}-$mice. In addition, the ratio of aa replacement to silent mutations ( $R / S$ ratio) in the complementarity determining region $1+2$ region was similar between WT and Eaf2 ${ }^{-1-}$ GC B cells (Fig. 6b, right panel).

We have also calculated the ratio of NP2- and NP25-binding antibody titres in WT and Eaf2 $2^{-1-}$ mice (Fig. 6c). Although the differences did not reach statistical significance, the ratio of NP2/ NP25 was reduced in Eaf2 ${ }^{-1-}$ mice compared with WT mice during the peak of GC reaction (1-3 weeks of primary responses and after boosting). These observations, along with the significantly decreased production of NP-specific high-affinity $\mathrm{Ab}$ and $\mathrm{AFC}$ in $R a g 1^{-7-}$ mice reconstituted with Eaf2 ${ }^{-1-} \mathrm{B}$ cells (Fig. 5e,f) and the moderate reduction of mutation frequency in the $V_{H} 186.2$ gene (Fig. 6a), collectively suggest a partial impairment in $\mathrm{Ab}$ affinity maturation in Eaf2 $2^{-1-}$ mice.

EAF2 regulates $B c l-2$ and $B b c 3 /$ Puma expression in GC B cells. EAF2 is a transcription elongation-associated factor. To identify potential Eaf2 target genes in GC B cells, we compared the gene
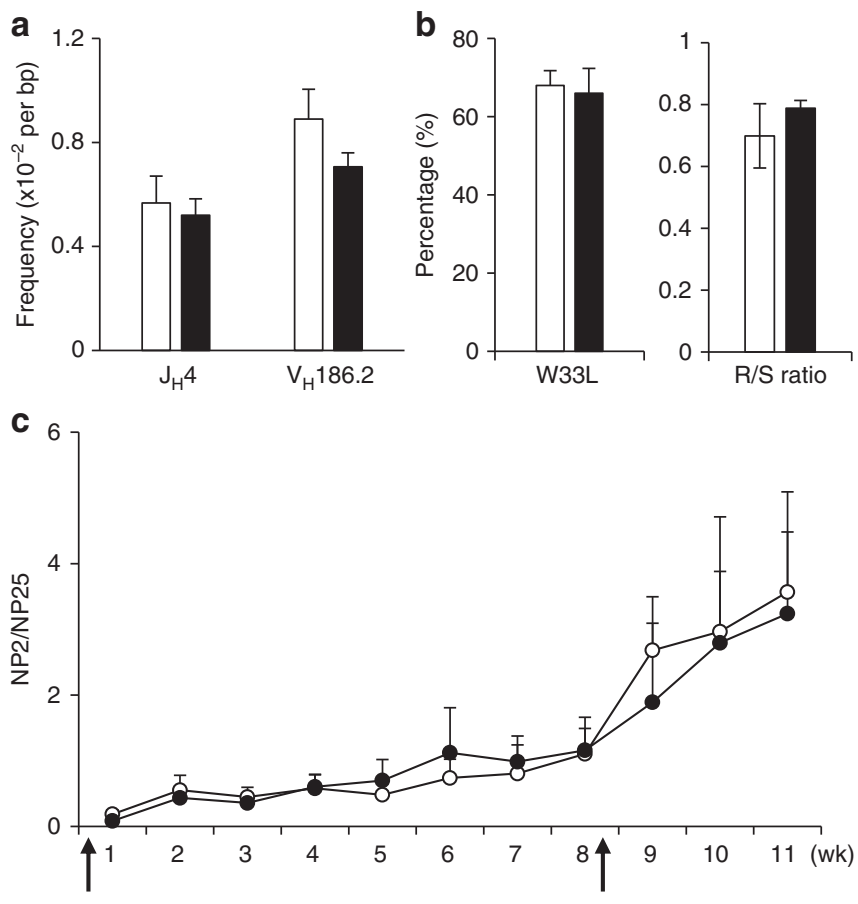

Figure 6 | Normal Ab affinity maturation in Eaf2 ${ }^{-/}$mice. (a) Mutation frequency in the $J_{H} 4$ intronic region and in the $V_{H} 186.2$ gene in GC B cells isolated from the spleen of WTand Eaf2 ${ }^{-/}-$mice immunized with NP-CGG. For the $J_{H} 4$ intronic region, 251 and 236 unique clones collected from 3 WT and 2 Eaf2 ${ }^{-/}-$mice, respectively, were analysed. For the $V_{H} 186.2$ gene, 177 WT and 117 Eaf2 ${ }^{-/-}$unique sequences form 2 WT and 2 Eaf2 ${ }^{-/-}$mice were analysed. (b) Left, frequency of the tryptophan to leucine substitution at position 33 (W33L). Right, ratio of aa replacement to silent mutations (R/S ratio) in CDR and FWR. Open bar, WT; Solid bar, Eaf2 ${ }^{-/-}$mice. (c) Ratio of NP2- and NP25-binding Ab titres in WT (open circles) and Eaf2- /(solid circles) mice, calculated from the data shown in Fig. 5a. The arrows indicate immunization time.

expression profiles between WT and Eaf2-I- GC B cells by microarray. Only 268 genes showed significantly differential expression between WT and Eaf2 ${ }^{-1-}$ GC B cells. A number of apoptosis-related genes, including $B c l 2 l 10, B c l 6 b, B i k, B a g 3, B c l-2$, $B b c 3, B c l 2 a 1 d, B c l 7 c$ and $B c l 2 l 15$ genes, were found to be up- or downregulated in Eaf2 ${ }^{-I}$ GC B cells. We focused on these apoptosis-related genes and verified their expression by semi-quantitative PCR with reverse transcription (RT-PCR). We found that the transcript level of the anti-apoptotic gene $\mathrm{Bcl}-2$ was increased while the level of the proapoptotic gene Bbc3/puma was decreased in Eaf2 ${ }^{-1}-$ GC B cells relative to WT GC B cells (Fig. 7a). Furthermore, we confirmed the upregulation of BCL-2 protein expression in Eaf2 ${ }^{-1-} \mathrm{B}_{22} 20^{+} \mathrm{PNA}^{+} \mathrm{GC} \mathrm{B}$ cells by intracellular staining (Fig. 7b). The mean fluorescence intensity of BCL-2 was $68.2 \pm 4.4$ in Eaf2 $2^{-1-}$ and $56.3 \pm 4.2$ in WT GC B cells $(P<0.05$, unpaired $t$-test). The transcript levels of the other apoptosis-related genes were either similar between WT and Eaf2-1- GC B cells or undetectable in both cells using our semi-quantitative RT-PCR analyses. To further verify that EAF2 regulated $B c l-2$ and $B b c 3 /$ puma expression, we ectopically expressed EAF2 in spleen B cells. As shown in Fig. 7c, expression of EAF2-IRES-GFP, but not GFP alone (CT), indeed downmodulated $B c l-2$ and upregulated $B b c 3$ transcript levels. Moreover, ectopic expression of EAF2 also induced apoptosis in a human Burkitt's lymphoma line Daudi (Supplementary Fig. 7a,b), which again was accompanied by decreased BCL-2 protein expression (Supplementary Fig. 7c) and increased BBC3 

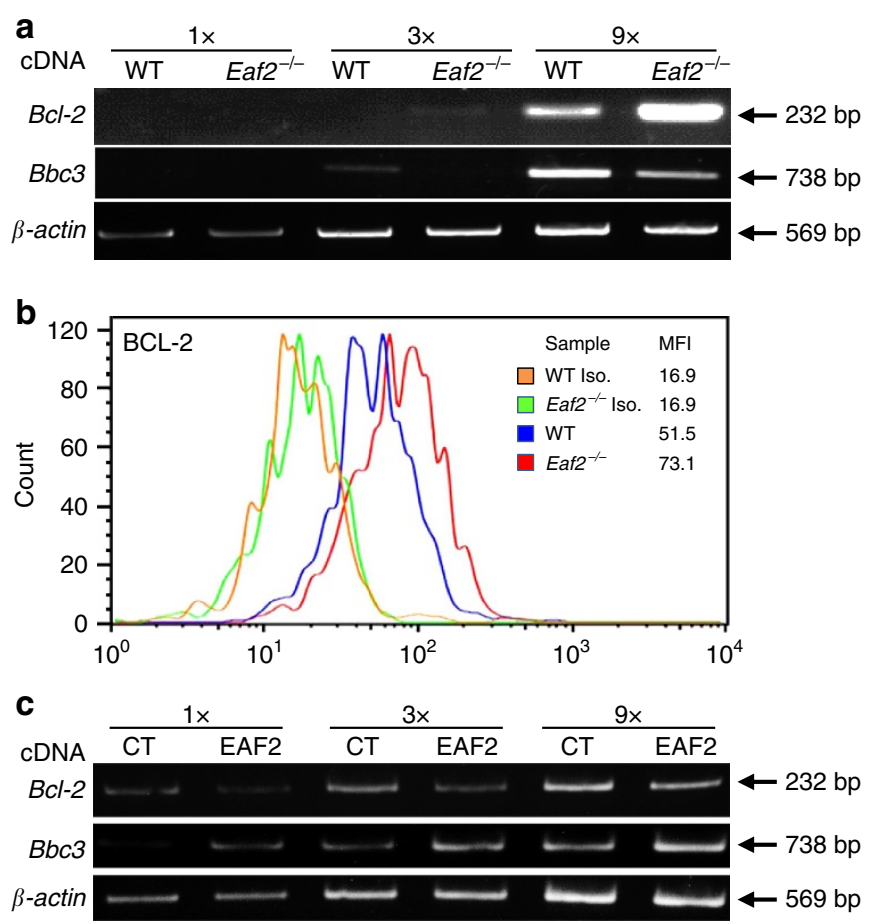

Figure 7 | EAF2 regulates Bcl-2 and Bbc3/Puma expression in GC B cells. (a) Semi-quantitative RT-PCR analysis of $\mathrm{BCl}-2$ and $\mathrm{Bbc} 3$ expression in sorted WT and Eaf2-/- GC B cells. Increasing amounts of the template cDNA were used. $\beta$-actin was used as an internal control. (b) Intracellular staining of BCL-2 in GC B cells of WT and Eaf2 ${ }^{-/-}$mice. Mean fluorescence intensity (MFI) is shown in the upper right. Blue, WT; Red, Eaf $2^{-1-}$; Orange and green, isotype control of WT and Eaf2 ${ }^{-} /-$. Similar results were obtained in three independent experiments. (c) Ectopic EAF2 expression downmodulated $\mathrm{BCl}-2$ and upregulated $\mathrm{Bbc} 3$ transcription in spleen B cells. Purified spleen B cells were cultured for $24 \mathrm{~h}$ in the presence of $10 \mu \mathrm{g} \mathrm{ml}^{-1}$ of LPS and then transduced with retrovirus expressing EAF2IRES-GFP (EAF2) or GFP alone (CT). Cells were harvested $24 \mathrm{~h}$ after retroviral transduction and subjected to RT-PCR analysis. Representative results of 3 experiments are shown.

transcript level (Supplementary Fig. 7d). Collectively, these results suggest that EAF2 promotes GC B-cell apoptosis both in mouse and human in part via targeting the expression of $\mathrm{Bcl}-2$ family genes.

Loss of EAF2 exacerbated CIA. SHM can generate self-reactive GC B cells, some of which may not be deleted but differentiate into autoantibody producing plasma cells under certain conditions $^{31}$. The impaired apoptosis of GC B cells in Eaf2 ${ }^{-1-}$ mice might facilitate the escape of the self-reactive GC B cells from the deletion process, allowing their differentiation into plasma cells secreting self-reactive Abs. This possibility was examined in a CIA model, which is mainly induced by autoantibodies against type II collagen $(\mathrm{CII})^{32}$. We immunized WT $(n=7)$ and Eaf2 ${ }^{-}(n=7)$ mice with chicken CII in Complete Freund's Adjuvant (CFA) and boosted them on day 20. Three WT and Eaf2 ${ }^{-I-}$ mice were injected with the same volume of PBS in CFA as a control. By day 3 after the boost, 3 Eaf2 ${ }^{-I}-$ but none of the WT mice developed arthritis symptoms and by day 9, 6 Eaf2 ${ }^{-1-}$ but only 3 WT mice showed signs of the disease (Fig. 8a, upper panel). None of the WT or Eaf2 ${ }^{-1-}$ mice that received PBS in CFA developed arthritis (Fig. 8a). In addition to the increased incidence of arthritis in Eaf2 ${ }^{-1}$ mice, their disease severity was also significantly elevated, as shown by the higher clinical scores compared with WT mice (Fig. 8a, lower panel). Histological analysis revealed greater synovial hyperplasia, joint narrowing and bone/cartilage erosion in the joints of arthritic Eaf2 ${ }^{-9}$ - mice as compared with arthritic WT mice (Fig. 8b).

CIA pathogenesis is largely mediated by CII-specific autoantibodies that bind to cartilage. We therefore determined the levels of anti-mouse CII autoantibodies in the sera on day 41 after the initial immunization. As shown in Fig. 8c, Eaf2 $2^{-1-}$ mice produced 5-, 3.3- and 6.4-fold more CII-specific IgG, $\mathrm{IgG}_{1}$ and $\operatorname{IgG}_{2 \mathrm{a}} \mathrm{Ab}$, respectively, than WT mice. No anti-CII Ab was detected in mice injected with PBS in CFA. Collectively, these findings suggest that CII-specific self-reactive GC B cells may not be efficiently eliminated in the absence of EAF2, allowing them to differentiate into plasma cells and produce different classes of $\mathrm{CII}-$ specific $\mathrm{Ab}$ that contribute to the pathogenesis of arthritis.

Spontaneous autoantibody production in aged Eaf2 $2^{-/-}$mice. We further investigated whether the impaired apoptosis of GC B cells would lead to spontaneous autoantibody production in aged mice even in the absence of deliberate immunization or other external stimuli. As shown in Fig. 8d, WT mice had a mean of $2.5 \mathrm{U} \mathrm{ml}^{-1}$ (ranging from 2.1 to 3.2 ) of anti-dsDNA Ab. In contrast, Eaf2 ${ }^{-1}-$ mice had a mean of $9.1 \mathrm{U} \mathrm{ml}^{-1}$ (ranging from 2.6 to 28.0 ) of the anti-dsDNA Ab, 8 of 11 Eaf2 ${ }^{-1-}$ mice had $>5 \mathrm{U} \mathrm{ml}^{-1}$ and 3 mice had $>10 \mathrm{U} \mathrm{ml}^{-1}$ of the anti-dsDNA Ab. In addition, Eaf2 $2^{-1}$ mice also produced an average of 1.8 -fold more IgG rheumatoid factor Ab than the WT mice, with 6 of 11 mice producing significantly increased rheumatoid factor levels (Fig. 8e). In fact, 9 of 11 Eaf $2^{-1}$ - mice produced elevated levels of either anti-dsDNA or rheumatoid factor, or both. We also examined the anti-nuclear Ab (ANA) in the sera of WT and Eaf $2^{-1-}$ mice using the HEp-2 ANA assay. Of the 7 Eaf2 ${ }^{-1-}$ mice analysed, all produced ANA, with six mice showing a homogeneous staining pattern and one showing a centromere pattern (Supplementary Fig. 8a,f), staining patterns characteristic of autoantibodies from systemic lupus erythematosus and systemic sclerosis patients, respectively. In contrast, only one of five WT mice produced ANA with a homogeneous staining pattern (Supplementary Fig. 8a,f). The titres of total serum IgG were no different between the aged WT and Eaf2 ${ }^{-1}$ mice (Supplementary Fig. 8b), indicating that the increased levels of autoantibodies in Eaf2 ${ }^{-1-}$ mice were not due to generally elevated levels of total serum IgG. These results suggest that Eaf2 ${ }^{-I}$ - mice accumulate various autoantibodies as they age likely due to the impaired elimination of self-reactive GC B cells.

\section{Discussion}

In the present study, we have identified EAF2, a transcription elongation-associated factor, as an apoptosis inducer for GC B but not naive $B$ and other immune cell types. Absence of EAF2 resulted in enlarged GC accompanied by decreased GC B-cell apoptosis in response to the T-D Ag NP-CGG. In addition, Eaf2 ${ }^{-1}$ - GC B cells contained an increased proportion of non-proliferating, possibly low affinity and/or Ag-nonspecific, GC B cells. Consistent with these observations, Ab affinity maturation was partially impaired in Eaf2 $2^{-1}$ mice as shown by a mild reduction in the ratio of high-affinity NP-specific $A b$ during the peak of GC reaction, a significant decrease in the production of high-affinity $\mathrm{Ab}$ in $\mathrm{Ragl}^{-/}$mice received Eaf2 ${ }^{-1}-$ B cells, and a moderate reduction in the mutation frequency of the $V_{H} 186.2$ gene. It is intriguing to note while Eaf2 ${ }^{-1}$ mice had increased production of both total and high-affinity NP-specific Ab and AFC as compared with WT mice, Rag1-1- mice reconstituted with Eaf2 ${ }^{-/-}$B cells had 

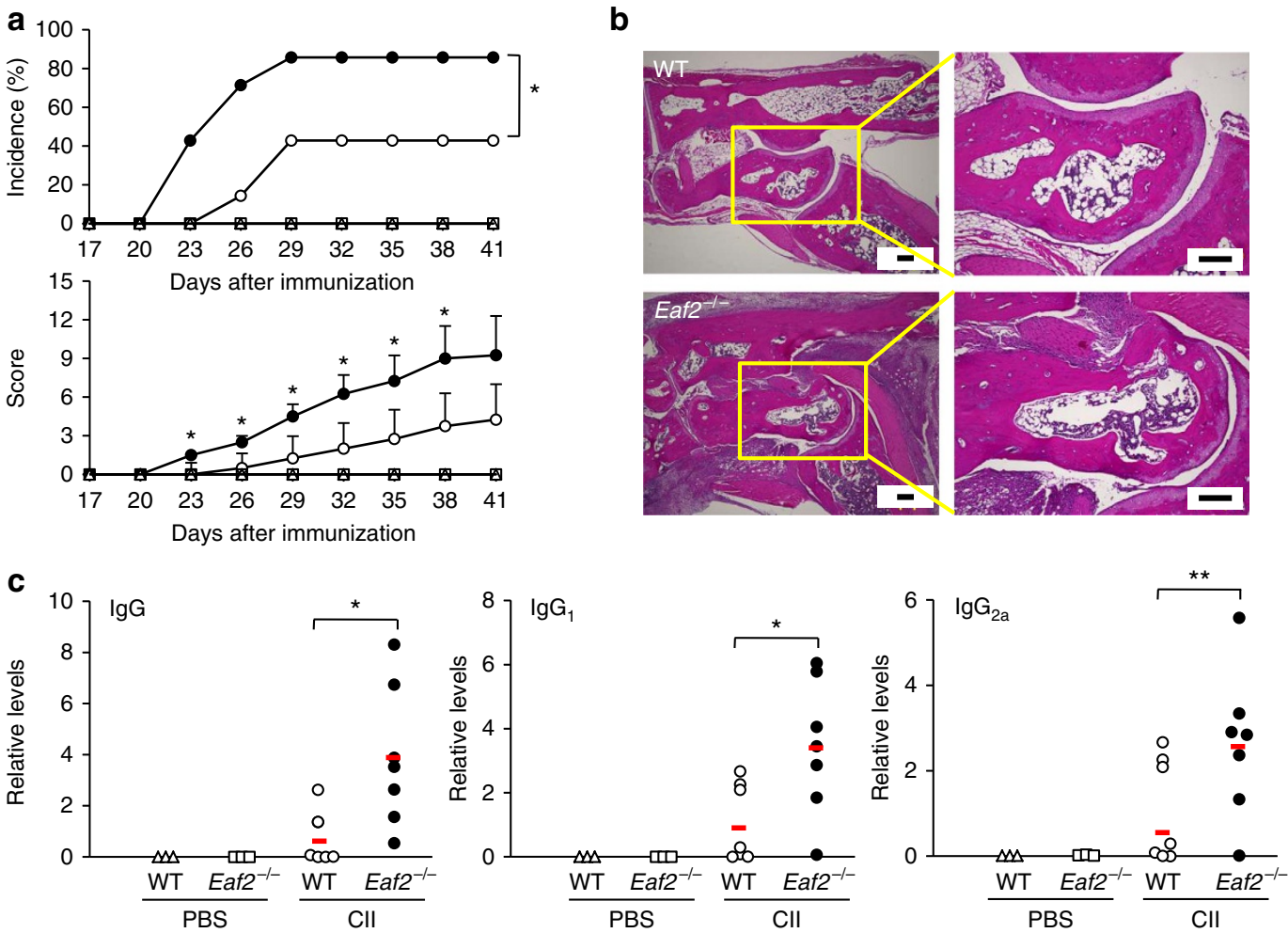

d

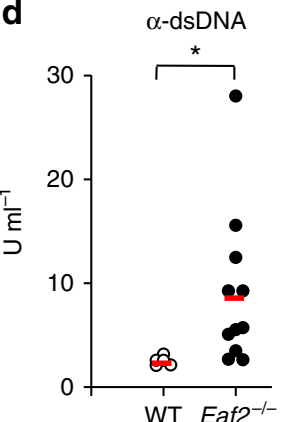

e

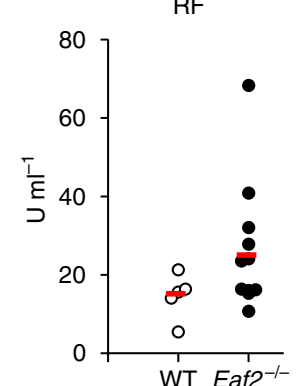

b
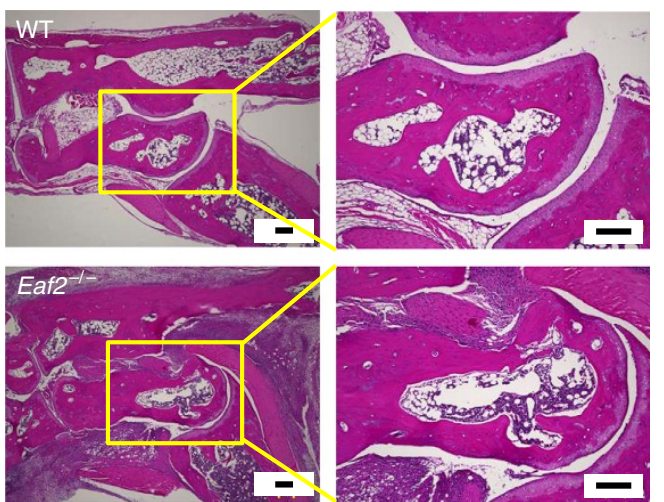

f

\section{WT}
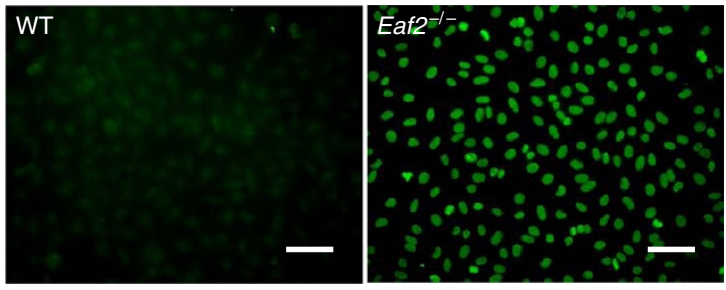

Figure 8 | Increased susceptibility to CIA and autoantibody production in Eaf2 $\mathbf{I}^{-}$mice. (a) Incidence (upper) and clinical scores (lower) of CIA in WT and Eaf2 $-/$ - mice. Seven pairs of WT and Eaf2 $-/-$ mice were injected with PBS or immunized with $\mathrm{CII}$ on day 0 and day 20 . Incidence and clinical scores of CIA were recorded every 3 days between days 20 and 41. Open triangles, PBS-injected WT mice; open squares, PBS-injected Eaf2 $-/$ - mice; open circles, Cll-immunized WT mice; solid circles, Cll-immunized Eaf2 ${ }^{-/}$- mice. ${ }^{\star} P<0.05$ (upper panel, log-rank test; lower panel, unpaired $t$-test).

(b) Haematoxylin and eosin (H\&E) staining of ankle joints (original magnifications: left, $\times 40 ;$ right, $\times 100$ ). Bars, 200 $\mu$ m. (c) Elevated levels of the Cllspecific $\operatorname{lgG}, \operatorname{lgG}_{1}$ and $\operatorname{lgG}_{2 a}$ Ab in Eaf2 ${ }^{-/-}$mice. The red bar indicates the mean value of each group. ${ }^{\star} P<0.05,{ }^{\star \star} P<0.01$ (unpaired $t$-test) (d-f) Aged (17 month old) Eaf2 $2^{-/}$mice produce increased levels of anti-dsDNA Ab, rheumatoid factor (RF) and ANA. Levels of anti-dsDNA Ab (d) and RF (e). Open circle, WT; solid circle, Eaf2 ${ }^{-/-}$mice. The red bar indicates the mean value of each group. Results of 5 WT and 11 Eaf2 $-/-$ mice are shown. ${ }^{\star} P<0.05$ (Fisher's exact test). (f) ANA. HEp-2 cells (obtained from RIKEN BioResource Center, Japan) were stained with sera from 5 WT and 7 Eaf2 $-/-$ mice (1:80 dilution). Of five WT mice, only one mouse produced ANA. In contrast, all 7 Eaf $2^{-/}-$mice produced ANA, with six mice showing a homogenous staining pattern and one mouse a centromere pattern $(P<0.05$, Fisher's exact test). Bars, $100 \mu$ m. Detailed results are shown in Supplementary Fig. 8a.

increased production of total $\mathrm{Ab}$ and $\mathrm{AFC}$ but decreased production of high-affinity $\mathrm{Ab}$ and $\mathrm{AFC}$ compared with those received WT B cells. We think that while Eaf2 ${ }^{-/-}$mice contained increased proportion of low-affinity GC B cells, high-affinity GC B cells were able to outcompete low-affinity GC B cells for both Ag binding and presentation to $\mathrm{T}_{\mathrm{FH}}$ cells, leading to their selective proliferation and differentiation into AFC (refs 33-35). In contrast, Rag $1^{-1-}$ mice reconstituted with purified $\mathrm{B}$ and $\mathrm{T}$ cells may not allow efficient expansion of the high-affinity GC B cells due to a defective follicular dendritic cell network and/or additional defect in GC formation, resulting in poor generation of high-affinity $\mathrm{AFC}$ and $\mathrm{Ab}$. In this scenario the enhanced survival of the low-affinity Eaf2-I- GC B cells would result in elevated production of low-affinity $\mathrm{AFC}$ and $\mathrm{Ab}$ at the expense of the production of high-affinity AFC and Ab.

While the selection for the high-affinity GC B cells was only moderately affected in Eaf2 ${ }^{-9}$ mice, the elimination of self-reactive GC B cells appeared to be impaired, as suggested by the finding that Eaf2 ${ }^{-I-}$ mice produced 3.3-6.4-fold more CII-specific autoantibodies than did WT mice in response to CII immunization. We postulate that GC B cells that have low or no affinity for a foreign $\mathrm{Ag}$ need not be actively eliminated by apoptosis since such B cells are unable to compete with the highaffinity GC B cells for the limited amount of foreign Ag to receive 
a survival and activation signal for their continued expansion. It is the self-reactive GC B cells that need to be actively eliminated by apoptosis to prevent their differentiation into Ab-producing plasma cells.

In addition to the high susceptibility to CIA and the production of increased levels of CII-specific autoantibodies, Eaf2 ${ }^{-1}-$ mice also produced anti-dsDNA, rheumatoid factor and ANA as they aged even though the mice were maintained under specific pathogen free conditions and in the absence of any additional genetic defect or any extrinsic stimuli such as an infection. Recent studies suggest that ANA arise predominantly from non-self-reactive $B$ cells that are transformed into selfreactive cells by the process of SHM, presumably during the GC reaction ${ }^{36,37}$. GC B cells undergo massive apoptosis and some of the apoptotic cells are not efficiently removed. Such apoptotic cells may be the source of self Ag including dsDNA and nuclear $\mathrm{Ag}$ (ref. 31). Absence of EAF2 may allow the survival of selfreactive GC B cells that are generated by SHM. Over time, some of these GC B cells might react with self Ag in the GC and differentiate into plasma cells that produce autoantibodies. It remains to be elucidated where and how plasma cells producing self-reactive $\mathrm{Ab}$ are generated in Eaf2 ${ }^{-1}-$ mice. GC reactions are continuously occurring in the intestine in response to bacteria and food Ag and it is conceivable that self-reactive GC B cells can be generated in these structures. Collectively, the present study suggests that EAF2 mediates B-cell apoptosis to eliminate selfreactive GC $B$ cells and this mechanism is critical for the prevention of autoantibody production and autoimmunity.

We have shown that EAF2 is involved in FAS-mediated apoptosis. In agreement with our finding, the phenotypes in Eaf2 ${ }^{-1}-$ and in $l p r$ and B-cell-specific FAS-deficient mice have some similarities ${ }^{17,38}$. Both Eaf2 ${ }^{-1-}$ and FAS-deficient mice have an increased proportion of GC B cells after immunization ${ }^{17}$. In addition, despite the increase of total GC B cells, both mutant mice have relatively normal-affinity maturation in serum $\mathrm{Ab}$. Most importantly, both $E a f 2^{-I^{-}}$and $l p r$ mice produce autoantibodies. However, following immunization, Eaf2 $2^{-1-}$ mice have a transient expansion of Ag-specific GC B cells and a prolonged increase in Ag-specific AFC, which are not observed in $l p r$ or FAS-deficient mice. Moreover, $l p r$ mice have greatly increased numbers of memory $\mathrm{B}$ cells during the late primary response with altered GC selection against affinity-enhancing mutants $^{16}$ while Eaf2 ${ }^{-/-}$mice only exhibit a moderate and transient increase in the memory B population with comparable GC selection. The differential phenotypes may be also due to the fact that Eaf2-1- GC B cells are only partially resistant to FAS-mediated apoptosis. These observations suggest that EAF2 and FAS have overlapping but distinct functions in regulating apoptosis in GC B, AFC and memory B cells.

We found that EAF2 deficiency resulted in increased $B c l-2$ and decreased Bbc3/puma expression and conversely ectopic EAF2 expression downmodulated $\mathrm{Bcl}-2$ and upregulated $\mathrm{Bbc3}$ expression. Attempts to demonstrate that EAF2 directly targets $B c l-2$ and $B b c 3$ genes have been unsuccessful either due to the quality of our EAF2 antibodies or because EAF2 indirectly regulates $\mathrm{Bcl}-2$ and $\mathrm{Bbc3}$ transcription. Proteins of the BCL-2 family play a critical role in controlling the humoral immune response ${ }^{39}$. Transgenic mice overexpressing the BCL-2 protein in $B$ cells were characterized by increased numbers of memory $B$ cells and AFC (ref. 11). Bcl-xL transgenic mice exhibited fewer apoptotic cells in GC and an increase in the numbers of AFC, especially in spleen, after immunization compared with WT mice $^{13}$. Eaf2 ${ }^{-1-}$ mice therefore have some similarity to the $B c l-2$ - and $B c l-x L$ transgenic mice in terms of the increased numbers of AFC for prolonged periods. The numbers of Ag-specific GC B and memory B cells are increased only transiently in Eaf2 ${ }^{-/-}$mice, which is different from the long-term increase of the Ag-specific memory B cells observed in $\mathrm{Bcl}$-2-transgenic mice. Mice deficient in BIM or NOXA showed enlarged GC (refs 35,40,41). Loss of BBC3/PUMA resulted in increased memory B cells but did not perturb B-cell activation in vitro or GC formation in vivo ${ }^{42}$. EAF2 deficiency did not affect the expression of Bim and Noxa but caused reduced expression of Bbc3/Puma. Therefore, EAF2 may promote GC B-cells apoptosis and restrict GC sizes through the combined effects of BCL-2 down modulation and Bbc3/Puma upregulation, as well as regulation of additional apoptosis-related proteins. While $\mathrm{Bcl}-2$ transgenic and BIM-deficient mice developed autoimmunity 43,44 , this was accompanied by altered lymphocyte development and strikingly increased numbers of B cells in these mice. In contrast, Eaf2 ${ }^{-9}$ mice showed normal lymphocyte development and maturation and only GC B cells exhibited impaired apoptosis. Therefore, Eaf2 ${ }^{-1}$ mice represent a unique autoimmune-prone mouse model predominantly caused by the impaired GC B-cell apoptosis.

In vitro and in vivo functional assays indicated that EAF2 has a tumour suppressive role in prostate cancer ${ }^{21}$. Eaf2 knockout mice on a mixed genetic background developed lung adenocarcinoma, hepatocellular carcinoma, B-cell lymphoma, and high-grade prostate intraepithelial neoplasia while EAF2 deficiency on a C57BL/6 background developed prostatic intraepithelial neoplasia but lacked macroscopic tumours in other organs ${ }^{24,45}$. Consistent with these observations, we have not observed lymphoma or other tumours in our Eaf2 $-1-$ mice which are generated on a pure $\mathrm{C} 57 \mathrm{BL} / 6$ background. Intriguingly, as they aged our Eaf2 ${ }^{-I}$ mice had an increased percentage of $\mathrm{B} 220^{+}$cells and a higher proportion of large $B$ cells than the WT mice (Supplementary Fig. 9a-c). Southern blot analysis using a $\mathrm{J}_{\mathrm{H}}$ probe revealed that both WT and Eaf2 ${ }^{-/}$spleen B cells had some retention of the germline band but otherwise showed a smear of bands (Supplementary Fig. 9d), suggesting that there was no obvious monoclonal expansion of pre-leukaemic B-cell clone(s) in these mice. These observations suggest that the impaired apoptosis in Eaf2 $2^{-/}$mice resulted in gradual accumulation of polyclonally activated B cells, some of which may undergo malignant transformation depending on the genetic background and/or environmental factors.

In conclusion, we have identified EAF2 as an apoptosis inducer of GC B but not naive B and other immune cell types. Absence of EAF2 resulted in excessive humoral immune responses and autoantibody production, indicating that EAF2 plays an important role in the maintenance of immune balance. Further studies are required to elucidate how EAF2 regulates its target gene expression and induces apoptosis in GC B cells. EAF2 is expressed in human tonsil and Daudi Burkitt's lymphoma cells, as well as in normal B cells and several other immune cell types according to the BioGPS database ${ }^{46}$. In addition, EAF2 was shown to be differentially expressed in lupus patients homozygous for the lupus-associated MECP2 risk versus protective haplotype ${ }^{47}$ and it will be of interest to explore the role of EAF2 in the development and/or progression of human autoimmune diseases.

\section{Methods}

Retrovirus transduction. Naive spleen B cells were purified from C57BL/6 mice by using a B cell negative purification kit (IMag beads, 557792, BD Biosciences). Purified B cells were cultured in the presence of $10 \mu \mathrm{g} \mathrm{ml}^{-1} \mathrm{LPS}$ for $24 \mathrm{~h}$ and then transduced with retrovirus expressing GFP alone or EAF2-IRES-GFP as described previously $^{48}$. Briefly, $4 \mu \mathrm{g}$ of pMX-IRES-GFP or pMX-EAF2-IRES-GFP constructs were transfected into $1.5 \times 10^{6}$ packaging cells using Lipofectamine (11668-019, Thermo Fisher Scientific) and $48 \mathrm{~h}$ later the culture supernatant containing the retrovirus was collected by centrifuging at $8,000 \mathrm{~g}$ for $16 \mathrm{~h}$. The precipitated retrovirus was resuspended in $1 \mathrm{ml}$ of culture medium (without antibiotics) and 
$0.4 \mathrm{ml}$ of the retrovirus was added to $1 \times 10^{5}$ cells in 24-well plates and centrifuged for $1 \mathrm{~h}$ at $32^{\circ} \mathrm{C}, 2,000$ r.p.m. The cells were further cultured for 24 and $48 \mathrm{~h}$, followed by staining with Annexin-V and 7-amino-actinomycin D (7-AAD; 559763, BD Biosciences) to detect apoptotic and dead cells, respectively.

Construction of the Eaf2 targeting vector. The targeting vector was constructed by using a MunI-MunI (3047-bp) and a BamHIII-ApaI (5090-bp) genomic fragment as $5^{\prime}$ and $3^{\prime}$ homologous regions, respectively, to replace Eaf2 exon 1 containing the translation initiation ATG codon with a neomycin (neo) gene flanked by loxP sites.

Generation of Eaf2 ${ }^{-/-}$mice. The Eaf2 targeting construct was linearized with PvuI and electroporated $(250 \mathrm{~V}, 500 \mu \mathrm{F})$ into C57BL/6-derived Bruce4 embryonic stem cells. Two days after the transfection, the embryonic stem cells were cultured in the presence of $600 \mu \mathrm{g} \mathrm{ml}^{-1}$ of G418 (G7034, Sigma) and $2 \mu \mathrm{M}$ of ganciclovir (078-04481, WAKO Chemicals, Japan; only for the first 2 days) for positive and negative selection of the targeted cells, respectively. Correctly targeted embryonic stem cell clones were microinjected into C57BL/6 blastocysts, and the embryos were transferred into foster mothers. Chimeric mice were generated and bred with C57BL/6 mice to obtain heterozygotes, which were further bred to obtain homozygotes. The mice were maintained under specific pathogen-free conditions in the animal facilities of the RIKEN Center for Integrative Medical Sciences and the Institute of Medical Science, the University of Tokyo. Protocols approved by the Animal Studies Committees of RIKEN Yokohama Institute and the University of Tokyo were used for all animal experiments.

RT-PCR analysis. For Eaf2 expression, primers s 214 and as 562 were used and the PCR was performed at $95^{\circ} \mathrm{C}$ for 2 min followed by 30 cycles of $95^{\circ} \mathrm{C}$ for $10 \mathrm{~s}, 55^{\circ} \mathrm{C}$ for $20 \mathrm{~s}$ and $72^{\circ} \mathrm{C}$ for $1 \mathrm{~min}$. For mouse $B c \mathrm{cl}$ and $\mathrm{Bbc3} / \mathrm{puma}$ expression, the following primer sets were used: $B c l-2 / s 809, B c l-2 / a s 1040, B b c 3 / p u m a / s 759$ and Bbc3/puma/as1496. PCR was performed at $95^{\circ} \mathrm{C}$ for 2 min followed by 35 cycles of $95^{\circ} \mathrm{C}$ for $10 \mathrm{~s}, 60^{\circ} \mathrm{C}$ for $10 \mathrm{~s}$ and $72^{\circ} \mathrm{C}$ for $1 \mathrm{~min}$. For human $B B C 3 / P U M A$ expression, $\mathrm{h} B B C 3 / \mathrm{s} 791$ and $\mathrm{h} B B C 3 / \mathrm{as} 1339$ primers were used. PCR was performed at $95^{\circ} \mathrm{C}$ for $2 \mathrm{~min}$ followed by 35 cycles of $95^{\circ} \mathrm{C}$ for $10 \mathrm{~s}, 60^{\circ} \mathrm{C}$ for $10 \mathrm{~s}$ and $72^{\circ} \mathrm{C}$ for $1 \mathrm{~min}$. The primers sequences are listed in Supplementary Table I.

In vitro culture of Peyer's patch cells. GC cells isolated from Peyer's patches of three pairs of WT and Eaf2 $2^{-1-}$ mice (16 weeks old) were added to 96-well plates $\left(1 \times 10^{6} \mathrm{cell} \mathrm{ml}^{-1}, 100 \mu \mathrm{l}\right.$ per well $)$ and cultured in medium alone, or in the presence of $\mathrm{CD} 40 \mathrm{~L}$ (threefold dilution of culture supernatants from a myeloma cell line producing soluble CD40L (ref. 49)), $5 \mu \mathrm{g} \mathrm{ml}^{-1} \mathrm{~F}\left(\mathrm{ab}^{\prime}\right)_{2}-\alpha-\operatorname{IgM}$ (16-5092-85, eBioscience) plus $20 \mathrm{ng} \mathrm{ml}^{-1} \mathrm{IL}-4$ (404-ML-010, R\&D systems), or $1 \mu \mathrm{g} \mathrm{ml}^{-1}$ agonistic $\alpha$-FAS Ab (554254, BD Biosciences). Six and $24 \mathrm{~h}$ later, cells were collected and stained with FITC-PNA (FL-1071, Vector Laboratories, 1600x dilution), APC-B220 (103211, Biolegend, 200x dilution), and Annexin-V and 7-AAD (559763, BD Biosciences) to detect apoptotic and dead cells.

Spleen histology. Three pairs of WT and Eaf2 ${ }^{-1-}$ mice (12 weeks old) were killed on day 14 after immunization with NP-CGG (N-5055C-5, Biosearch Technologies), and their spleens were removed and embedded in Tissue Tek OCT compound (23-730-571, Fischer Scientific) by flash-freezing in liquid $\mathrm{N}_{2}$. Blocks of frozen tissue were stored at $-80^{\circ} \mathrm{C}$ until sectioning ${ }^{50}$. Spleens were cut on a cryostat as $5-\mu \mathrm{m}$-thick sections and thaw mounted onto MAS-coated slides. Sections were allowed to air dry for $10 \mathrm{~min}$, and stored at room temperature until use. We analysed spleen sections from the largest circumference, and measured the sizes of $>20$ GCs from each mouse to determine the average GC size.

PNA staining of spleen sections. Before immunohistochemical staining, spleen sections were fixed in ice-cold acetone for $10 \mathrm{~min}$. Endogenous peroxidase activity was blocked by $10 \mathrm{~min}$ room temperature incubation in $0.3 \% \mathrm{H}_{2} \mathrm{O}_{2}$ before staining. Sections were stained in 300-fold diluted biotinylated PNA (B-1075, Vector Laboratories) for $1 \mathrm{~h}$ in a humidified chamber, followed by Streptavidin-alkaline phosphatase (AP) (7100-04, SouthernBiotech). Bound AP was then visualized by enzymatic detection with $0.125 \mathrm{mg} \mathrm{ml}^{-1}$ of naphthol-AS-MX phosphate $(855$ $20 \mathrm{ML}$, Sigma), $0.25 \mathrm{mg} \mathrm{ml}^{-1}$ Fast Blue BB salt (44670, Sigma) and $2 \mathrm{mM}$ levamisole (1359302, Sigma) in $0.1 \mathrm{M}$ Tris- $\mathrm{HCl}(\mathrm{pH} 8.5)^{8}$. Ten min later, stained sections were washed in PBS and mounted in 30\% glycerol.

TUNEL assay. Two pairs of WT and Eaf2 $2^{-l-}$ mice (12 weeks old) were immunized and their spleen sections were prepared as described for spleen histology and PNA staining. Endogenous peroxidase activity was blocked by 10 min room temperature incubation in $0.3 \% \mathrm{H}_{2} \mathrm{O}_{2}$ before staining, followed by washing with PBS. Sections were then incubated for $60 \mathrm{~min}$ in a $37^{\circ} \mathrm{C}$ humidified incubator with terminal deoxynucleotidyl transferase enzyme in the presence of reaction buffer (S7100, Apoptag In situ detection kit, Chemicon International) ${ }^{51}$ After washing three times with PBS, digoxigenin was added on the section for $30 \mathrm{~min}$ in a $37^{\circ} \mathrm{C}$ humidified incubator. Sections were counterstained with PNA as described above. Horseradish peroxidase (HRP)-labelled TUNEL ${ }^{+}$cells were visualized using $0.4 \mathrm{mg} \mathrm{ml}^{-1} 3$-amino-ethyl-carbazole (A6926, Sigma) and $0.005 \%$ $\mathrm{H}_{2} \mathrm{O}_{2}$ in $0.05 \mathrm{M}$ sodium acetate buffer ( $\mathrm{pH} 5.0$ ). TUNEL ${ }^{+}$cells were counted at a magnification of $\times 200$ by systematic scanning of the entire section. Counts were confirmed by blinded recounts.

EdU incorporation assay. EdU incorporation was performed using a Click-iT EdU Alexa Fluor kit (C10419, ThermoFisher) according to the manufacturer's instruction. Briefly, $5 \mathrm{WT}$ and $6 \mathrm{Eaf2} \mathrm{2}^{-1-}$ mice (10 weeks old) were immunized with NP-CGG and 12 days and 13 days later injected intraperitoneal (i.p.) with $200 \mu \mathrm{l} \mathrm{of}\left(1 \mathrm{mg} \mathrm{m}^{-1}\right)$ EdU. EdU incorporation was analysed on day 14 by FACS

Detection of NP-specific GC and memory B cells. B cells were purified from spleen of age-matched immunized WT and Eaf2 ${ }^{-1-}$ mice (five pairs, $10-11$ weeks old) by negative sorting using a B-cell enrichment set (557792, BD Biosciences).

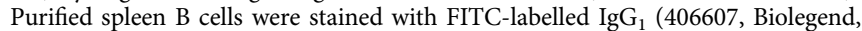
100x dilution), PE-conjugated $\mathrm{NIP}_{26}$-BSA (a kind gift from Dr Takemori, 500x dilution), APC-conjugated anti-CD38 (303510, Biolegend, 40x dilution) and PE-Cy7-labelled anti-B220 (561881, BD Biosciences, 80x dilution). GC B cells (NIP binding $/ \mathrm{B}_{22} 20^{+} / \mathrm{IgG}_{1}^{\text {dull }} / \mathrm{CD} 38^{\text {dull }}$ ) and memory B cells (NIP binding/ $\mathrm{B}_{22} 0^{+} / \mathrm{IgG}_{1}^{\text {high }} / \mathrm{CD} 38^{+}$) were analysed by FACSCalibur (BD Biosciences).

Immune response. For T-D Ab production, five pairs of WT and Eaf2 $2^{-1-}$ mice (8 weeks old) were injected i.p. with $10 \mu \mathrm{g}$ of NP-CGG in alum and boosted with $10 \mu \mathrm{g}$ of NP-CGG in PBS 8-weeks later. For T-I Ab production, five pairs of WT and Eaf2 $2^{-1-}$ mice (8 weeks old) were immunized with $10 \mu \mathrm{g}$ of NP-Ficoll (F-1420, Biosearch Technologies). Mice were bled weekly from the retro-orbital sinus and the serum titres of NP-specific $\operatorname{IgG}_{1}, \operatorname{IgM}$ or $\operatorname{IgG}_{3}$ were analysed. For measuring NP-specific high and total (high and low affinity) Ab, plates (NUNC AIS, Denmark) were coated with $50 \mu \mathrm{l}$ per well of $2.5 \mathrm{\mu g} \mathrm{ml}^{-1}$ of NP2-BSA (N-5050L, Biosearch Technologies, NP2 plate) and $2.5 \mathrm{\mu g} \mathrm{ml}^{-1}$ of NP25-BSA (N-5050H, Biosearch Technologies, NP25 plate), respectively, in PBS overnight, followed by blocking with 1\% BSA in PBS. After washing with $0.05 \%$ Tween 20 in PBS, sera at various dilutions were added and the plates were then incubated for $1 \mathrm{~h}$ at room temperature. The bound immunoglobulin was detected using HRP-conjugated goat $\mathrm{Ab}$ specific to each mouse Ig isotype (SouthernBiotech) and developed for $20 \mathrm{~min}$ using an ABTS solution. Serial dilutions of the control high (clone C6) and low (clone N1G9) affinity NP-specific Ab were included to determine the concentrations of NP2-binding (high affinity) and NP25-binding (total) Ab, respectively. Since the high-affinity Ab are known to bind to NP25-BSA inefficiently, the amount of NP-specific total Ab (measured with NP25-BSA using N1G9 as a control) was likely underestimated.

For determination of anti-collagen II Ab, immunosorbent plates were coated with $5 \mu \mathrm{g} \mathrm{ml}^{-1}$ of chicken type II collagen (20012, Chondrex) in $10 \mathrm{mM}$ acetic acid overnight. After blocking with $10 \%$ BSA in $0.05 \%$ T-PBS for $2 \mathrm{~h}$, sera serially diluted with $0.5 \%$ BSA in $0.05 \%$ T-PBS were added into the plate and incubated for $2 \mathrm{~h}$ at room temperature. After washing, HRP-conjugated goat anti-mouse IgG, IgM, IgG or $\mathrm{IgG}_{2 \mathrm{a}} \mathrm{Ab}$ were added and incubated for $1 \mathrm{~h}$ at room temperature, and 1-Step Ultra TMB ELISA substrate (34028, Thermo) was added to each well. The colour reaction was stopped with $1.2 \mathrm{M} \mathrm{H}_{2} \mathrm{SO}_{4}$ and the absorbance at $450 \mathrm{~nm}$ wavelength was measured.

ELISPOT assay. ELISPOT assay was performed using a Multiscreen HTS filter plate (Millipore). The HTS plate was coated with $50 \mu \mathrm{g} \mathrm{ml}^{-1}$ of NP2-BSA or NP25-BSA at $4{ }^{\circ} \mathrm{C}$ overnight. The coated plate was then washed three times with PBS-T (PBS containing 0.1\% Tween 20) and blocked with PBS containing $1 \%$ BSA for $1 \mathrm{~h}$ at room temperature. Splenocytes $\left(3 \times 10^{5}, 1.5 \times 10^{5}\right.$ and $\left.0.75 \times 10^{5}\right)$ were then seeded and incubated at $37^{\circ} \mathrm{C}$ for $100 \mathrm{~min}$ in a $\mathrm{CO}_{2}$ incubator. The plate was then washed twice with PBS-T containing $50 \mathrm{mM}$ EDTA, three times with PBS-T and blocked again with PBS containing $1 \%$ BSA for $1 \mathrm{~h}$ at room temperature. The plate was further incubated with AP-conjugated goat anti-mouse $\mathrm{IgG}_{1} \mathrm{Ab}\left(1 \mu \mathrm{g} \mathrm{ml}{ }^{-1}\right.$ in PBS containing $\left.1 \% \mathrm{BSA}\right)$ at $37^{\circ} \mathrm{C}$ for $60 \mathrm{~min}$ in a $\mathrm{CO}_{2}$ incubator, washed four times with PBS-T and developed with BCIP/NBT reagent (MOSS INC) for 2-3 min. The plate was then washed four times with $\mathrm{H}_{2} \mathrm{O}$, air dried and colonies were counted using an IMMUNOSPOT Analyzer (CTL Analyzers LLC). The number of colonies obtained with different numbers of splenocytes was converted to number of colonies per $10^{6}$ cells and the mean values are shown.

Adoptive transfer. These experiments were performed as described previously ${ }^{48}$ Briefly, spleen B cells were purified from 5 WT or 5 Eaf2 $2^{-1-}$ mice (10 weeks old) and spleen T cells were purified from $3 \mathrm{WT}$ mice ( 10 weeks old). $1 \times 10^{7} \mathrm{~B}$ cells were mixed with $5 \times 10^{6} \mathrm{~T}$ cells and transferred into 9-week-old Rag1 ${ }^{-1}-$ mice of C57BL/6 background (CLEA Japan). One week after the transfer, the recipient mice were immunized i.p. with $100 \mu \mathrm{g}$ of NP-CGG and analysed for humoral immune responses 2 weeks later. 
Sorting of the GC B cells. WT and Eaf2 ${ }^{-1-}$ mice (9 weeks old) were immunized with $100 \mu \mathrm{g}$ of NP-CGG. Two weeks later, the splenic cells were stained with PE-B220 (103208, Biolegend, 200x dilution) and FITC-PNA and the B220 ${ }^{+} \mathrm{PNA}^{+}$ GC B cells were sorted using a FACSAria (BD Biosciences). Genomic DNA was isolated for the analysis of Ig gene SHM and total RNA was isolated for gene expression analysis.

Induction of CIA. CIA was induced as previously described ${ }^{32}$. Briefly, 9-week-old sex-matched WT (C57BL6/J) and Eaf2 ${ }^{-1-}$ mice (generated on a pure C57BL6/J background) were injected intravenously with $100 \mu \mathrm{l}$ of a $1 / 1(\mathrm{v} / \mathrm{v})$ emulsion of $0.05 \mathrm{M}$ acetic acid containing $100 \mu \mathrm{g}$ of chick type II collagen (20012, Chondrex) and CFA (7023, Chondrex). The day of the first immunization was defined as day 0 . Twenty days after the primary immunization, the mice were boosted with $100 \mu \mathrm{g}$ of collagen II in IFA via the same route. The severity of arthritis was evaluated every 3 days after the boost by visual inspection. Each paw was scored for clinical signs of arthritis as described ${ }^{52}$. The clinical score for each mouse was the sum of the four paw scores, which results in a maximum score of 16. On the final day of the experiments, all mice were anaesthetized and their blood was collected by cardiac puncture.

Histopathologic analysis. After completing the CIA experiments, mice were killed and hind paws were fixed in $4 \%$ phosphate-buffered paraformaldehyde solution, decalcified in Kalkitox (112-00651, Wako, Japan), and then embedded in paraffin. The tissues were longitudinally cut into $3-\mu \mathrm{m}$ serial sections and stained with haematoxylin and eosin. The histopathological changes in the joints were examined under light microscopy.

Detection of autoantibodies. For measuring the levels of anti-dsDNA and rheumatoid factor, anti-dsDNA (AKRDD-061, Lbis) and rheumatoid factor IgG (AKRRG-101, Lbis) mouse ELISA kits were used. For measuring ANA, mouse sera diluted at 1:80 were tested for ANA using a HEp-2 kit (ORG870, Orgentec). The HEp-2 slides were incubated with the diluted sera for $30 \mathrm{~min}$ followed by washing with PBS. Subsequently, the slides were stained with $1 \mu \mathrm{g} \mathrm{ml}^{-1}$ of Alexa Fluor-488goat anti-mouse IgG $(\mathrm{H}+\mathrm{L}) \mathrm{Ab}$ (A11029, Life technologies) and visualized using a fluorescence microscope.

Statistical analysis. Statistical significance was assessed by an unpaired or paired $t$-test, Fisher's exact test, or log-rank test $\left({ }^{*} P<0.05 ;{ }^{* *} P<0.01\right)$.

\section{References}

1. Peperzak, V., Vikstrom, I. B. \& Tarlinton, D. M. Through a glass less darkly: apoptosis and the germinal center response to antigen. Immunol. Rev. 247, 93-106 (2012).

2. Pulendran, B., Kannourakis, G., Nouri, S., Smith, K. G. \& Nossal, G. J. Soluble antigen can cause enhanced apoptosis of germinal-centre B cells. Nature 375, 331-334 (1995).

3. Shokat, K. M. \& Goodnow, C. C. Antigen-induced B-cell death and elimination during germinal-centre immune responses. Nature $\mathbf{3 7 5}, 334-338$ (1995).

4. Han, S., Zheng, B., Dal Porto, J. \& Kelsoe, G. In situ studies of the primary immune response to (4-hydroxy-3-nitrophenyl) acetyl IV. affinity-dependent, antigen-driven B cell apoptosis in germinal centers as a mechanism for maintaining self-tolerance. J. Exp. Med. 182, 1635-1644 (1995).

5. Chan, T. D. et al. Elimination of germinal-center-derived self-reactive B cells is governed by the location and concentration of self-antigen. Immunity 37 , 893-904 (2012).

6. Shlomchik, M. J., Marshak-Rothstei, A., Wolfowicz, C. B., Rothstein, T. \& Weigert, M. G. The role of clonal selection and somatic mutation in autoimmunity. Nature 328, 805-811 (1987).

7. Radic, M. Z. \& Weigret, M. Genetic and structural evidence for antigen selection of anti-DNAantibodies. Annu. Rev. Immunol. 12, 487-520 (1994).

8. Ray, S. K., Putterman, C. \& Diamond, B. Pathogenic autoantibodies are routinely generated during the response to foreign antigen: a paradigm for autoimmune disease. Proc. Natl Acad. Sci. USA 93, 2019-2024 (1996).

9. Danial, N. N. \& Korsmeyer, S. J. Cell death: critical control points. Cell 116, 205-219 (2004).

10. Strasser, A. et al. The role of bim, a proapoptotic BH3-only member of the Bcl-2 family in cell-death control. Ann. N Y Acad. Sci. 917, 541-548 (2000).

11. Smith, K. G., Weiss, U., Rajewsky, K., Nossal, G. J. \& Tarlinton, D. M. Bcl-2 increases memory B cell recruitment but does not perturb selection in germinal centers. Immunity 1, 803-813 (1994).

12. Smith, K. G. et al. bcl-2 transgene expression inhibits apoptosis in the germinal center and reveals differences in the selection of memory B cells and bone marrow antibody-forming cells. J. Exp. Med. 191, 475-484 (2000).

13. Takahashi, Y. et al. Relaxed negative selection in germinal centers and impaired affinity maturation in bcl-xL transgenic mice. J. Exp. Med. 190, 399-410 (1999).
14. Vikstrom, I. et al. Mcl-1 is essential for germinal center formation and B cell memory. Science 330, 1095-1099 (2010).

15. Strasser, A., Harris, A. W., Huang, D. C., Krammer, P. H. \& Cory, S. Bcl-2 and Fas/APO-1 regulate distinct pathways to lymphocyte apoptosis. EMBO J. 14, 6136-6147 (1995).

16. Takahashi, Y., Ohta, H. \& Takemori, T. Fas is required for clonal selection in germinal centers and the subsequent establishment of the memory B cell repertoire. Immunity 14, 181-192 (2001).

17. Hao, Z. et al. Fas receptor expression in germinal-center B cells is essential for $\mathrm{T}$ and B lymphocyte homeostasis. Immunity 29, 615-627 (2008).

18. Simone, F. et al. EAF1, a novel ELL-associated factor that is delocalized by expression of the MLL-ELL fusion protein. Blood 98, 201-209 (2001).

19. Simone, F., Luo, R. T., Polak, P. E., Kaberlein, J. J. \& Thirman, M. J. ELLassociated factor 2 (EAF2), a functional homolog of EAF1 with alternative ELL binding properties. Blood 101, 2355-2362 (2003).

20. Wang, Z., Tufts, R., Haleem, R. \& Cai, X. Genes regulated by androgen in the rat ventral prostate. Proc. Natl Acad. Sci. USA 94, 12999-13004 (1997).

21. Xiao, W. et al. Suppression of prostate tumor growth by U19, a novel testosterone-regulated apoptosis inducer. Cancer Res. 63, 4698-4704 (2003)

22. Kong, S. E., Banks, C. A., Shilatifard, A., Conaway, J. W. \& Conaway, R. C. ELL-associated factors 1 and 2 are positive regulators of RNA polymerase II elongation factor ELL. Proc. Natl Acad. Sci. USA 102, 10094-10098 (2005).

23. Qiao, Z., Wang, D., Hahn, J., Ai, J. \& Wang, Z. Pirin down-regulates the EAF2/ U19 protein and alleviates its growth inhibition in prostate cancer cells. Prostate 74, 113-120 (2014)

24. Pascal, L. E. et al. Development of a reactive stroma associated with prostatic intraepithelial neoplasia in EAF2 deficient mice. PLoS ONE 8, e79542 (2013).

25. Rose, M. L., Birbeck, M. S., Wallis, V. J., Forrester, J. A. \& Davies, A. J. Peanut lectin binding properties of germinal centres of mouse lymphoid tissue. Nature 284, 364-366 (1980).

26. MacLennan, I. C. Germinal centers. Annu. Rev. Immunol. 12, 117-139 (1994).

27. Lentz, V. M. \& Manser, T. Cutting edge: germinal centers can be induced in the absence of T cells. J. Immunol. 167, 15-20 (2001).

28. Frey, S. et al. Mismatch repair deficiency interferes with the accumulation of mutations in chronically stimulated B cells and not with the hypermutation process. Immunity 9, 127-134 (1998).

29. Jolly, C. J., Klix, N. \& Neuberger, M. S. Rapid methods for the analysis of immunoglobulin gene hypermutation: application to transgenic and gene targeted mice. Nucleic Acids Res. 25, 1913-1919 (1997).

30. Masuda, K. et al. DNA polymerase $\eta$ is a limiting factor for A:T mutations in Ig genes and contributes to antibody affinity maturation. Eur. J. Immunol. 38, 2796-2805 (2008).

31. Brink, R. The imperfect control of self-reactive germinal center B cells. Curr. Opin. Immunol. 28, 97-101 (2014).

32. Brand, D. D., Latham, K. A. \& Rosloniec, E. F. Collagen-induced arthritis. Nat Protoc. 1, 1269-1275 (2007).

33. Gitlin, A. D., Shulman, Z. \& Nussenzweig, M. C. Clonal selection in the germinal centre by regulated proliferation and hypermutation. Nature 509, 637-640 (2014).

34. Oropallo, M. A. \& Cerutti, A. Germinal center reaction: antigen affinity and presentation explain it all. Trends Immunol. 35, 287-289 (2014).

35. Fischer, S. F. et al. Proapoptotic BH3-only protein Bim is essential for developmentally programmed death of germinal center-derived memory B cells and antibody-forming cells. Blood 110, 3978-3984 (2007).

36. Schroeder, K., Herrmann, M. \& Winkler, T. H. The role of somatic hypermutation in the generation of pathogenic antibodies in SLE. Autoimmunity 46, 121-127 (2013).

37. Detanico, T. et al. Somatic mutagenesis in autoimmunity. Autoimmunity 46, 102-114 (2013).

38. Smith, K. G., Nossal, G. J. \& Tarlinton, D. M. FAS is highly expressed in the germinal center but is not required for regulation of the B-cell response to antigen. Proc. Natl Acad. Sci. USA 92, 11628-11632 (1995).

39. Youle, R. J. \& Strasser, A. The BCL-2 protein family: opposing activities that mediate cell death. Nat. Rev. Mol. Cell Biol. 9, 47-59 (2008).

40. Strasser, A. The role of BH3-only proteins in the immune system. Nat. Rev. Immunol. 5, 189-200 (2005).

41. Wensveen, F. M. et al. BH3-only protein Noxa regulates apoptosis in activated B cells and controls high-affinity antibody formation. Blood 119, 1440-1449 (2012).

42. Clybouw, C. et al. Regulation of memory B-cell survival by the BH3-only protein Puma. Blood 118, 4120-4128 (2011).

43. Strasser, A., Whittingham, S. \& Vaux, D. L. Enforced BCL2 expression in B-lymphoid cells prolongs antibody responses and elicits autoimmune disease. Proc. Natl Acad. Sci. USA 88, 8661-8665 (1991).

44. Bouillet, P. et al. Proapoptotic Bcl-2 relative Bim required for certain apoptotic responses, leukocyte homeostasis, and to preclude autoimmunity. Science 286, 1735-1738 (1999). 
45. Xiao, W. et al. U19/Eaf2 knockout causes lung adenocarcinoma, B-cell lymphoma, hepatocellular carcinoma and prostatic intraepithelial neoplasia. Oncogene 27, 1536-1544 (2008).

46. Wu, C. et al. BioGPS: an extensible and customizable portal for querying and organizing gene annotation resources. Genome Biol. 10, R130 (2009).

47. Webb, R. et al. Variants within $M E C P 2$, a key transcriptional regulator, are associated with increased susceptibility to lupus and differential gene expression in lupus patients. Arthritis Rheum. 60, 1076-1084 (2009).

48. Ouchida, R., Kurosaki, T. \& Wang, J. Y. A role for lysosomal-associated protein transmembrane 5 in the negative regulation of surface B cell receptor levels and B cell activation. J. Immunol. 185, 294-301 (2010).

49. Wang, J., Koizumi, T. \& Watanabe, T. Altered antigen receptor signaling and impaired Fas-mediated apoptosis of B cells in Lyn-deficient mice. J. Exp. Med. 184, 831-838 (1996).

50. Jacob, J., Kassir, R. \& Kelsoe, G. In situ studies of the primary immune response to (4-hydroxy-3-nitrophenyl)acetyl. I. The architecture and dynamics of responding cell population. J. Exp. Med. 173, 1165-1175 (1991).

51. Gavrieli, Y., Sherman, Y. \& Ben-Sasson, S. A. Identification of programmed cell death in situ via specific labeling of nuclear DNA fragmentation. J. Cell Biol. 119, 493-501 (1992).

52. Rosloniec, E. F., Cremer, M., Kang, A. H., Myers, L. K. \& Brand, D. D. Current Protocols in Immunology Chapter 15 unit 15.5, pp 1-25 (2010).

\section{Acknowledgements}

We wish to thank Profs Takeshi Tokuhisa, Hiroshi Ohno, Sidonia Fagarasan and Peter Burrows for helpful advice, and Akiko Ukai and Hiromi Mori for technical assistance. This work was in part supported by the National Basic Research Program of

China (2015CB943300 to J.Y.W.), the National Natural Science Foundation of China

(81373129 and 81571529 to J.Y.W.), and a grant-in-aid for scientific research (C) from Japan Society for the Promotion of Science (25460604 to J.Y.W.).

\section{Author contributions}

Y.L. designed and performed most of the experiments; Y.T., S.F., A.S. and T.T. helped in vivo experiments; Y.Z. and R.H. performed adoptive transfer and Southern blot; K.H. supervised all research and J.Y.W. designed the project and wrote the manuscript.

\section{Additional information}

Supplementary Information accompanies this paper at http://www.nature.com/ naturecommunications

Competing financial interests: The authors declare no competing financial interests.

Reprints and permission information is available online at http://npg.nature.com/ reprintsandpermissions/

How to cite this article: Li, Y. et al. EAF2 mediates germinal centre B-cell apoptosis to suppress excessive immune responses and prevent autoimmunity. Nat. Commun. 7:10836 doi: 10.1038/ncomms10836 (2016).

(c) (i) article are included in the article's Creative Commons license, unless indicated otherwise in the credit line; if the material is not included under the Creative Commons license, users will need to obtain permission from the license holder to reproduce the material. To view a copy of this license, visit http://creativecommons.org/licenses/by/4.0/ 